\title{
Priming food intake with weight control cues: systematic review with a meta- analysis
}

\author{
Nicola J. Buckland ${ }^{1 *}$ (D) Vanessa $\mathrm{Er}^{2}$, lan Redpath ${ }^{3}$ and Kristine Beaulieu ${ }^{4}$
}

\begin{abstract}
Background: A growing number of studies suggest that exposure to cues which are associated with weight control can prime or prompt controlled food intake in tempting food environments. However, findings are mixed and understanding which types of cues and for whom such cues may be most effective is needed to inform subsequent research and societal applications. A systematic review and meta-analysis were conducted to evaluate the effects of exposure to weight control cues compared with control cues on food intake.

Methods: PsycINFO, Medline, Embase and Web of Science were searched using key terms. Hedge's g was used to calculate effect sizes based on mean food intake, standard deviations and sample sizes extracted from relevant publications and, a random effects model was used for the meta-analysis.

Results: Twenty-five articles consisting of 26 studies were eligible. Data from 25 studies (31 effect sizes) were available for the meta-analysis. Overall, weight control cues reduced food intake, albeit to a trivial effect (ES: $-0.149,95 \%$ Cl: -0.271 to - 0.027). Subgroup analyses when studies which induced negative affect were removed showed that for individuals with strong weight control goals the effect was small-to-moderate (ES: $-0.440,95 \% \mathrm{Cl}$ : -0.718 to -0.163 ), whereas for individuals with weak weight control goals this effect was trivial and non-significant (ES: $0.014,95 \%$ Cl: -0.249 to 0.278 ). Cue type and level of engagement did not significantly moderate the effect; however, specific cues (low-calorie foods and thin models) and attended engagement yielded significant effects. Caution is needed interpreting these findings as most studies were rated with high risk of bias and a number of studies could not be included in the subgroup analyses.

Conclusions: Based on the data available, weight control cues reduce food intake in individuals with strong weight control goals. Further research is needed to explore longer term effects of cue exposure and confirm underlying mechanisms. PROSPERO registry\#CRD42016052396.
\end{abstract}

Keywords: Food intake, Goal priming, Weight control goals, Systematic review, Meta-analysis

\section{Background}

The current obesogenic environment presents constant exposure to palatable high energy dense foods and has been identified as a key driver of overconsumption and rising obesity rates $[1,2]$. Exposure to palatable food cues can increase physiological responses to food [3], anticipatory food reward [4] and food intake [5]. As such, it has been recognised that interventions which target environmental cues

\footnotetext{
* Correspondence: n.buckland@sheffield.ac.uk

${ }^{1}$ Department of Psychology, University of Sheffield, Cathedral Court, 1 Vicar Lane, Sheffield S1 2LT, England

Full list of author information is available at the end of the article
}

might offer an effective strategy to influence eating behaviour at the population level [6]. Indeed, there is a growing body of evidence that small alterations to the proximal environment can influence pro-health behaviours [6].

One way that environmental cues can influence behaviour is by activating or priming cognitions [7]. According to goal priming theorists, cues can activate cognitive goals and result in goal-directed behaviour [7]. While the cue exposure can occur at a conscious or subconscious level, the activation of goals occurs outside of conscious awareness. Applied to eating behaviour, this suggests that cues associated with weight control (e.g. scales, low calorie

(c) The Author(s). 2018 Open Access This article is distributed under the terms of the Creative Commons Attribution 4.0 International License (http://creativecommons.org/licenses/by/4.0/), which permits unrestricted use, distribution, and 
foods) can activate or prime weight control goals and lead to controlled or reduced food intake [8]. According to The Goal Conflict Theory, such effects will be more pronounced in individuals who hold relevant weight control goals [8]. In support, laboratory studies have reported that compared to control cues, exposure to weight control cues have reduced subsequent food intake in general samples $[9,10]$ and in individuals with strong weight control goals such as restrained eaters [11] and dieters [12, 13]. Other studies have reported that the effects of weight control cues are moderated by particular settings such as the time of day (effects in general sample) [14] and portion size (effects in restrained eaters only) [15]. The effects of weight control cues on food intake (in restrained eaters) have also been found in real world settings such as in response to a 'slimming poster' displayed on the entrance to a butcher's store [16]. These findings are important because they suggest that goal priming can be applied to population-level behaviour change interventions [17].

However, findings are mixed as some studies reported no effects of weight control cues on food intake $[18,19]$. Such discrepant findings might be due to the methodologies used across studies as the types of cues used, the level of cue engagement (for example, subliminal, incidental and attended) and the samples tested have largely varied. Understanding the effects of weight control cues and which types of cues, settings and for whom these cues might be most effective will be valuable to inform societal applications and subsequent research.

As such, a systematic review and meta-analysis of the evidence was conducted to identify the effectiveness of weight control cues on food intake and to investigate if the effects are moderated by the type of weight control cue used (cue type and level of engagement) and the extent to which participants hold weight control goals.

\section{Methods}

\section{Search strategy}

The systematic review and meta-analysis is reported in line with the preferred reporting items for systematic reviews and meta-analysis (PRISMA) guidelines. The protocol was registered in the PROSPERO database (International prospective register of systematic reviews; registration number: CRD42016052396). Four electronic databases were searched for articles published up to January 2017 (and the search was updated in March 2018): PsycINFO (from1806), Medline (from 1946), Embase (from 1947) and Web of Science (from 1864). The search included a combination of key words relevant to cues, weight control and food intake (Additional file 1). One author conducted the search and selected articles for full text screening based on article titles and abstracts (NB) and a second author (KB) checked $10 \%$ of articles (there were no disagreements). A manual search of eligible articles reference lists and citations was also conducted which identified two eligible articles [20, 21]. Authors of eligible studies were contacted to request for other published or unpublished studies to minimise publication bias. This resulted in two articles $[11,22]$ and one unpublished study being identified [23].

\section{Study eligibility criteria}

The search was limited to English-language papers, human studies and healthy adults aged 18-64 years. Studies were included if they exposed participants to cues associated with weight control and, during or after cue exposure, objectively measured food intake as either energy intake, weight consumed or piece count. Studies that used self-reported food intake, food choice or eating intentions were not included. Only food intake was assessed as it allows for the precise measurement of consumption [24], whereas food choice does not necessarily reflect intake and self-report measures are subject to underreporting [25]. To our knowledge, there is no formal definition or a database of validated cues that are associated with weight control cues. Therefore, we considered studies that used cues closely linked with dieting constructs (e.g. slim models, weighing scales, low calorie foods, weight management products and exercise-related cues) to be eligible. There were no disagreements between authors about whether a particular cue was regarded as a weight control cue or not. Cues more closely aligned to eating enjoyment cues (e.g. overweight body images, palatable food) were not considered to be weight control cues. Studies were included regardless of the theoretical approach used (e.g. some studies used exposure to slim models to manipulate negative body image, body dissatisfaction or motor priming [26] rather than priming weight control goals per se [20-22, 2730]). Exposure to cues could be either subliminal, incidental or explicit. Studies which administered cues after at least $5 \mathrm{~min}$ of access to snacks were excluded as this could have minimised the impact of cue exposure on food intake. ${ }^{1}$ Studies using food packaging labels as cues (e.g. 'low fat') were excluded to prevent any confusion over inconsistent food messages confounding food intake (e.g. 'healthy' cookies). Studies that had cues which incorporated negative messages about being overweight were excluded (e.g. body weight stigma) [31]. To prevent study duplications, $\mathrm{PhD}$ and Masters theses containing studies published in peer-reviewed journal articles were not included. Experimental, quasi-experimental and intervention studies which used either within- or between-subject designs were included. For quality control, only studies that included a control condition comprising of either no cue or a neutral cue were included; studies that compared weight control cues to eating enjoyment cues only (aimed at increasing food intake) and did not include a control 
condition were excluded. Two authors were responsible for screening full text articles (NB, KB). There were no disagreements.

\section{Data extraction}

One author extracted sample sizes, means and standard deviations of food intake in the cue and control conditions (KB). Another author (NB) checked that the extracted data corresponded with the data reported in papers (NB). One author (NB) extracted all other study information. The extracted data is shown in Table 1. Authors were contacted for missing sample sizes, means, standard deviations and units of outcome (grams or kcal). In instances when means and standards errors were provided for food intake, standard deviations were calculated [10, 21].

\section{Meta-analysis}

A specialty meta-analysis software was used for the analyses (Comprehensive Meta Analysis, version 3; Biostat, Englewood, NJ). Means, standard deviations and sample size for the cue exposure and control conditions were inputted into the software. For studies with multiple comparisons (e.g. [32]), sample sizes for each comparison were adjusted accordingly. In one study [19], means, sample size and $p$-value were used to compute the effect size (ES). The ES was calculated as Hedges's g to account for potential bias and the overall ES using a random effects model due to large variability in study designs and outcomes reported. A negative effect size value indicates that cue exposure decreased food intake whereas a positive effect size indicates that cue exposure increased food intake relative to no cue exposure. The effect sizes were interpreted as follows: $<0.2$ as trivial, $0.2-0.3$ as small, 0.5 as moderate, and $>0.8$ as large [33].
Heterogeneity was assessed using the $\mathrm{I}^{2}$ index, with values of $25 \%$ considered as low heterogeneity, $50 \%$ as moderate and $75 \%$ as high [34]. Sensitivity analyses were conducted by the software by excluding one study at a time to examine if results were affected by any one study in particular. Planned subgroup analyses were conducted to identify whether the effects of weight control cues on food intake was moderated by cue type, level of engagement and whether participants held weak or strong weight control goals. High restrained eaters, dieters and individuals with high self-discrepancy were combined and classified as those with strong weight control goals, and low restrained eaters, non-dieters and individuals with low self-discrepancy were classified as those with weak weight control goals (using restrained eating as an indicator for weight control goals is consistent with previous research [8]) (the decision to combine dieters, restrained eaters and self-discrepancy was made after data extraction and not pre-specified in the registered protocol). Exploratory moderator analyses were also conducted for categorical data, including sex, snack type, sample type, intake measure, use of appetite control procedures and theoretical model. To assess publication bias, Egger's regression [35] and the trim-and-fill method were used [36].

\section{Risk of bias}

Risk of bias was assessed using the Cochrane Collaboration's tool as closely as possible [37] (Additional file 2). Studies were evaluated for 'blinding of participants and personnel' and 'blinding of outcome assessors' based on the likelihood that participants were naive about food intake being assessed (i.e. use of a cover story and whether the cover story was believed), and whether the

Table 1 Description of data collected from included articles

\begin{tabular}{|c|c|}
\hline Criterion & Data extracted \\
\hline $\begin{array}{l}\text { Country research } \\
\text { conducted }\end{array}$ & Country \\
\hline Study design & Between-subjects, within-subject, laboratory, field. \\
\hline $\begin{array}{l}\text { Participant } \\
\text { characteristics }\end{array}$ & $\begin{array}{l}\text { Total sample size; number of male and female participants; mean, median, standard deviation and range for age and BMI and } \\
\text { BMI assessment method if assessed (self-report or objectively measured). }\end{array}$ \\
\hline Moderating variables & $\begin{array}{l}\text { Individual differences in eating behaviour traits [dieting status; restrained eating (scale used) or any other psychometric } \\
\text { scales]; any other moderators examined. }\end{array}$ \\
\hline $\begin{array}{l}\text { Cue type and level } \\
\text { of engagement }\end{array}$ & Type of cue: Specific item (e.g. slim models, foods); level of engagement: explicit, incidental, sub-conscious; cue validation \\
\hline Test food & Interval between cue exposure and assessment of food intake; Test foods used: snack, meal, sweet, savoury, food name. \\
\hline $\begin{array}{l}\text { Mechanism for effects } \\
\text { tested? }\end{array}$ & Yes, no; type of assessment used. \\
\hline Main outcome & Food intake in ounces, piece count, grams and energy intake; assessment method for food intake (weighed, piece count) \\
\hline Risk of bias & $\begin{array}{l}\text { Random allocation to conditions, randomisation methods, allocation concealment, blinding (use of a cover story and participants' } \\
\text { beliefs about the study aims; whether the researcher was aware of the study aims or condition that had been administered), } \\
\text { completion of outcome reporting (excluded participants), procedures used to control for appetite, individual or social setting, } \\
\text { administration of psychometric scales. }\end{array}$ \\
\hline
\end{tabular}


experimenter was blinded to the study aims or condition that had been administered. For 'other bias', studies were assessed based on the likelihood that confounding variables could have influenced food intake [for example piece count (high risk of researcher bias), the absence of procedures to control for appetite between conditions [38]; social settings [24, 39]; providing restricted food portions [24]; and administering psychometric scales prior to the assessment of food intake which may have increased body image awareness]. One author rated each study for risk of bias (NB) and decisions were cross-checked by another author (KB). Any disagreements were discussed and resolved between the two authors.

\section{Results}

Included studies

Figure 1 shows the article selection process. Of the 5583 articles identified, 25 were eligible for the systematic review which comprised of 26 studies. Of these, one article was excluded from the meta-analysis as the data (means, standard deviations and sample sizes) could not be obtained [28]. As such, the meta-analysis included 24 articles from which there were 25 studies (one article had two studies [26]) with 31 relevant comparisons (four studies included two comparisons $[10,14,15,40]$ and one included three [32]). For one study, different cues were used for males and females and only the cue used for females met the eligibility criteria [32]. Therefore, for that study, only the data for females were included in the systematic review and meta-analysis.

\section{Study designs and participants}

Table 2 displays characteristics of the eligible studies. Of the 26 studies, one was a field study [16] and all others were laboratory studies. All used between-subject designs except for two which used within-subject designs $[13,23]$. Eight studies were conducted in the USA [14, 19, 26, 32, 40-42], four in the UK [12, 13, 20, 23], three in Canada $[18,21,30]$, three in the Netherlands $[15,16,27]$, three in Switzerland $[9,11,43]$ two in Australia $[10,29]$, two in New Zealand [22, 28] and one in France [44].

Twelve studies used female participants only [12, 13, 18, 20-23, 27-30] (including the study where only the manipulation for females was deemed eligible [32]) and 14 used mixed-sex samples [9-11, 14-16, 19, 26, 40-44]. Of the mixed-sex samples, $42.6 \%$ were males. Eighteen

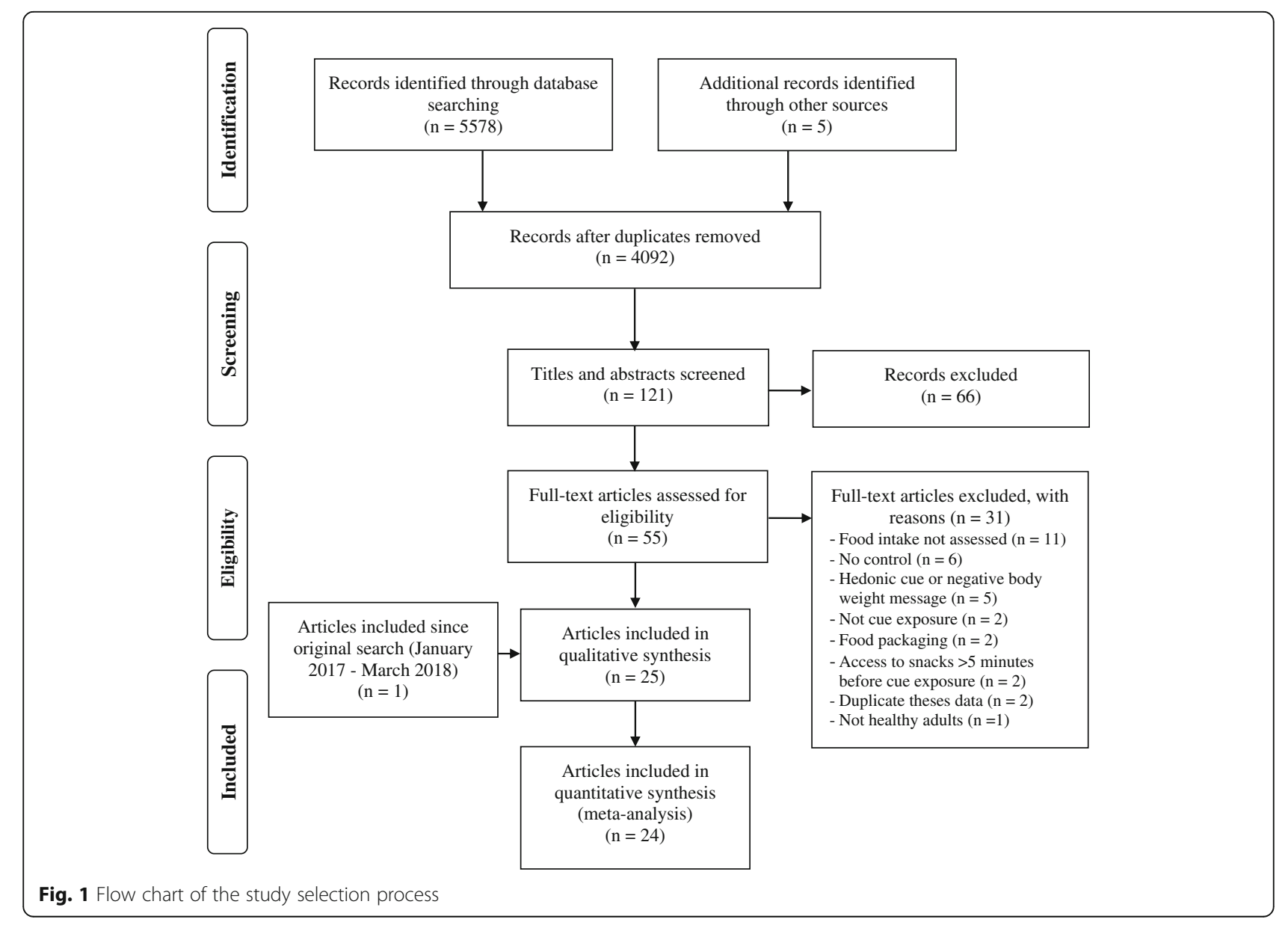




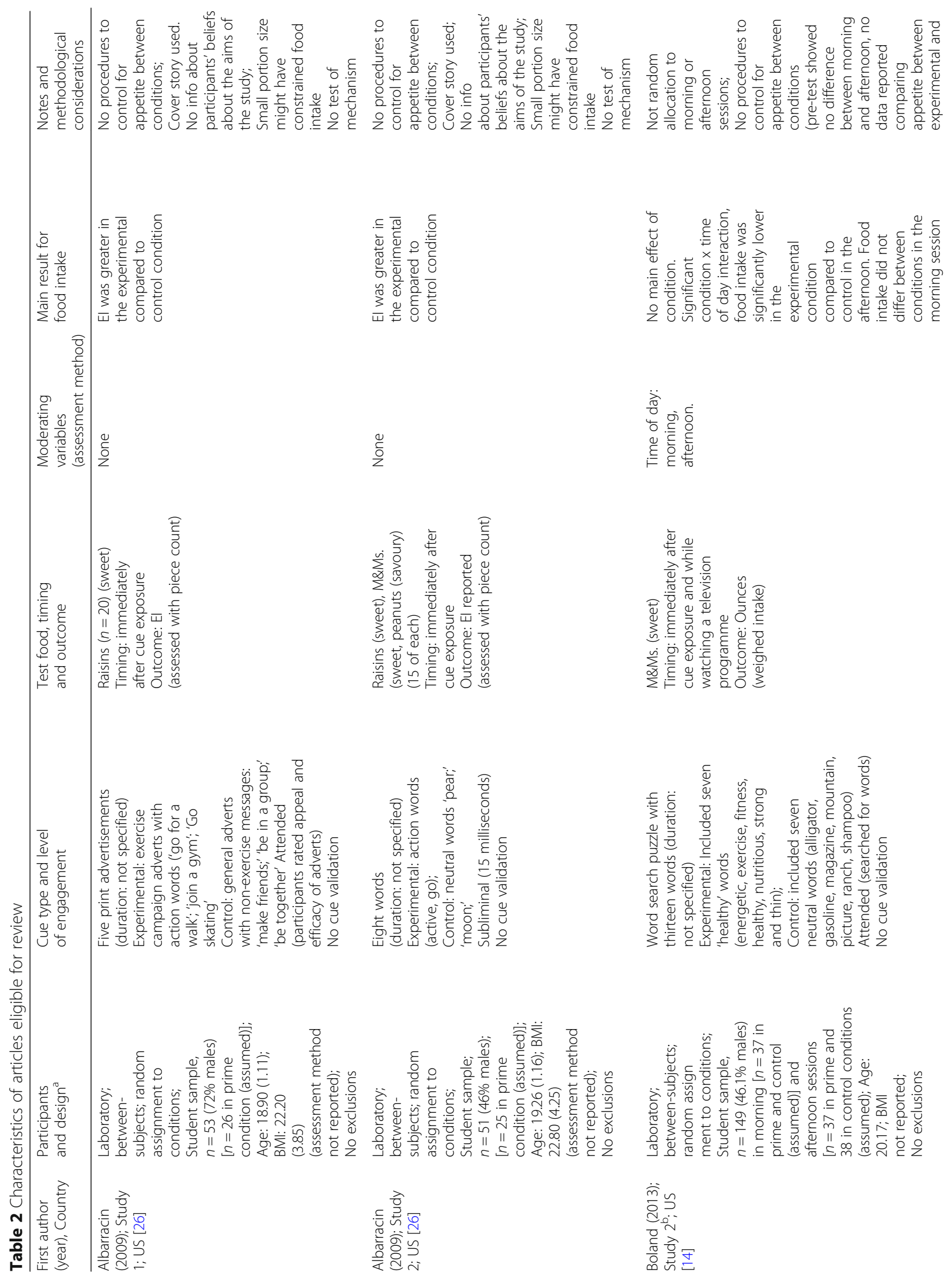




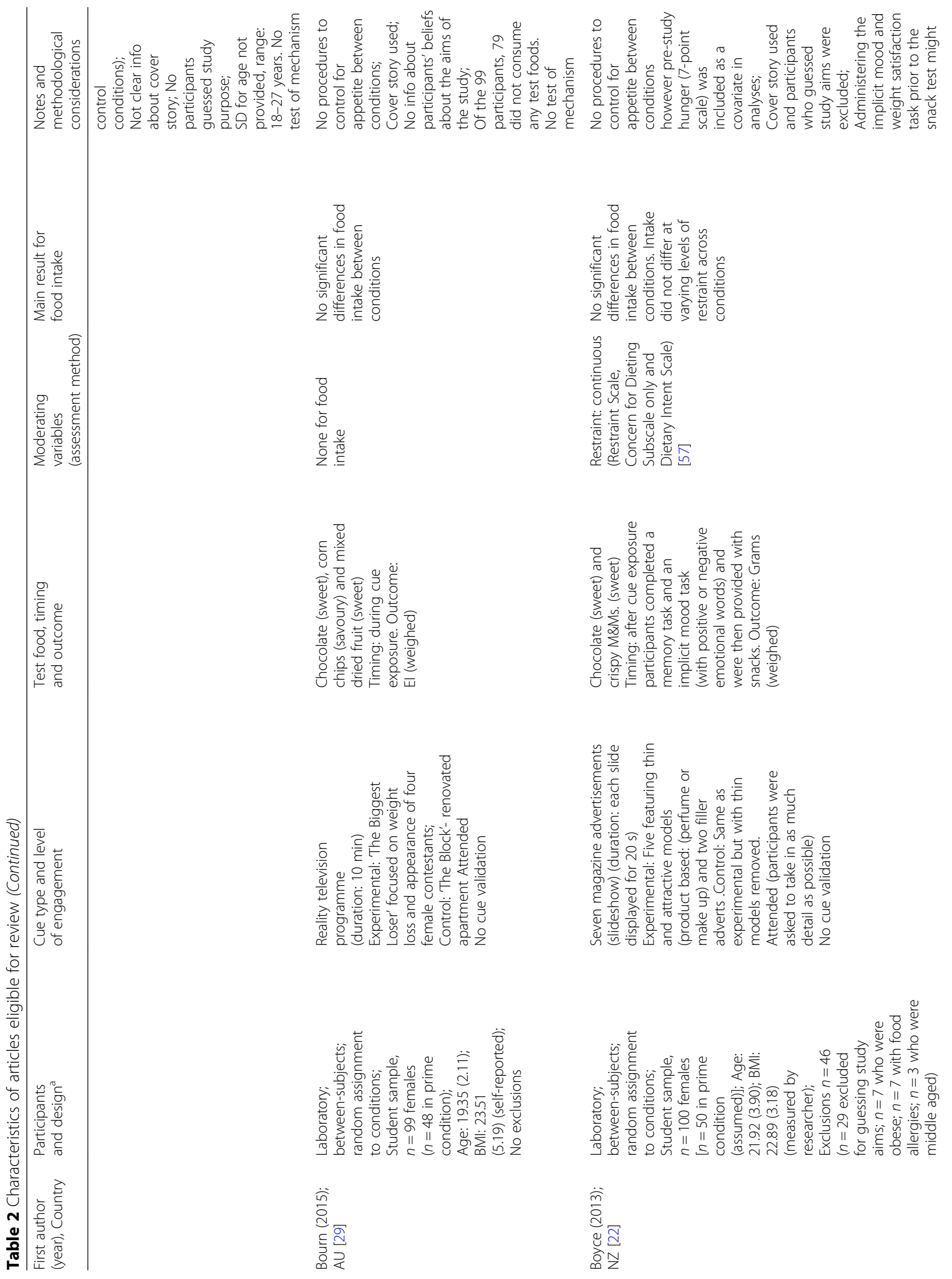




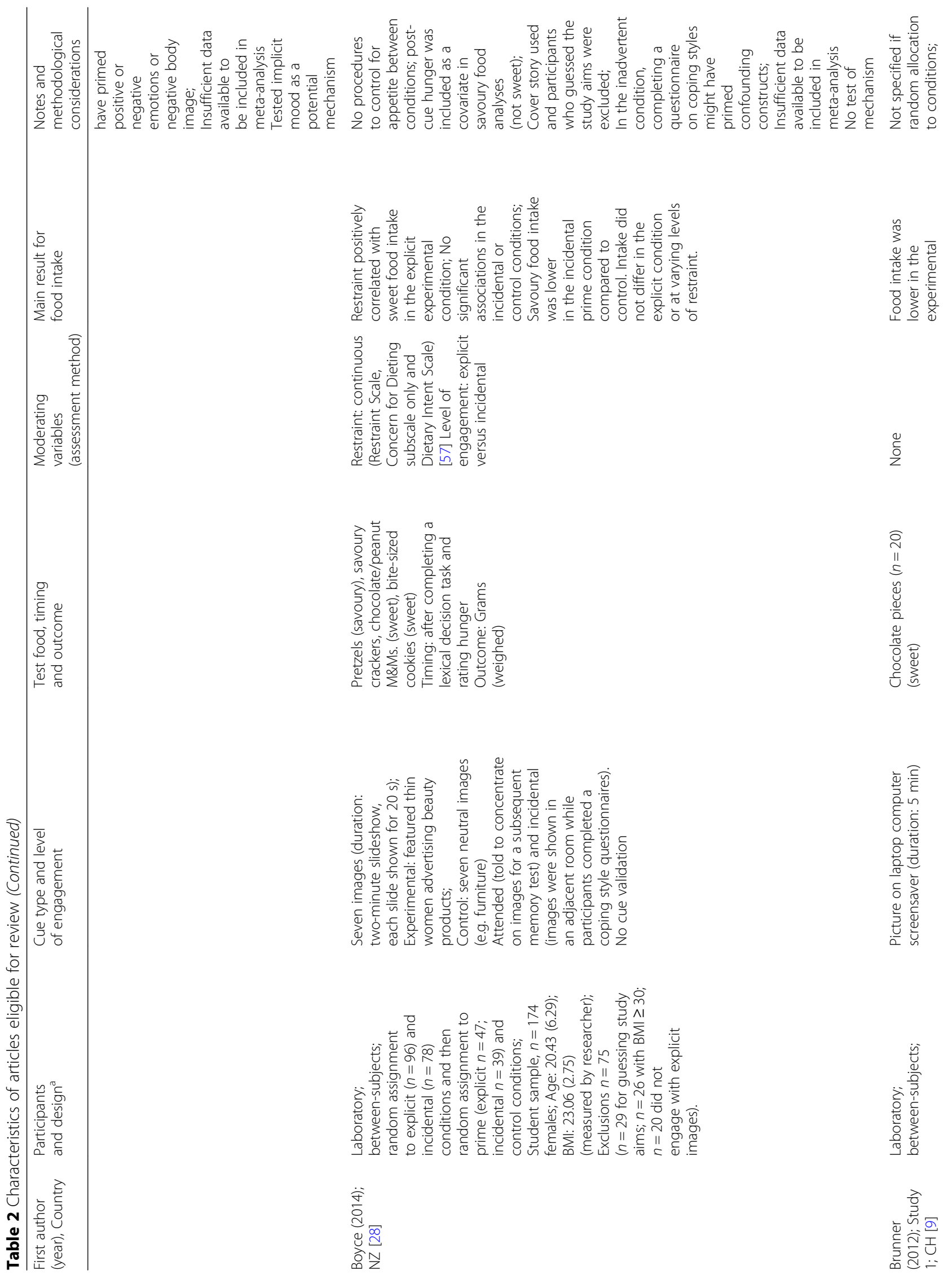




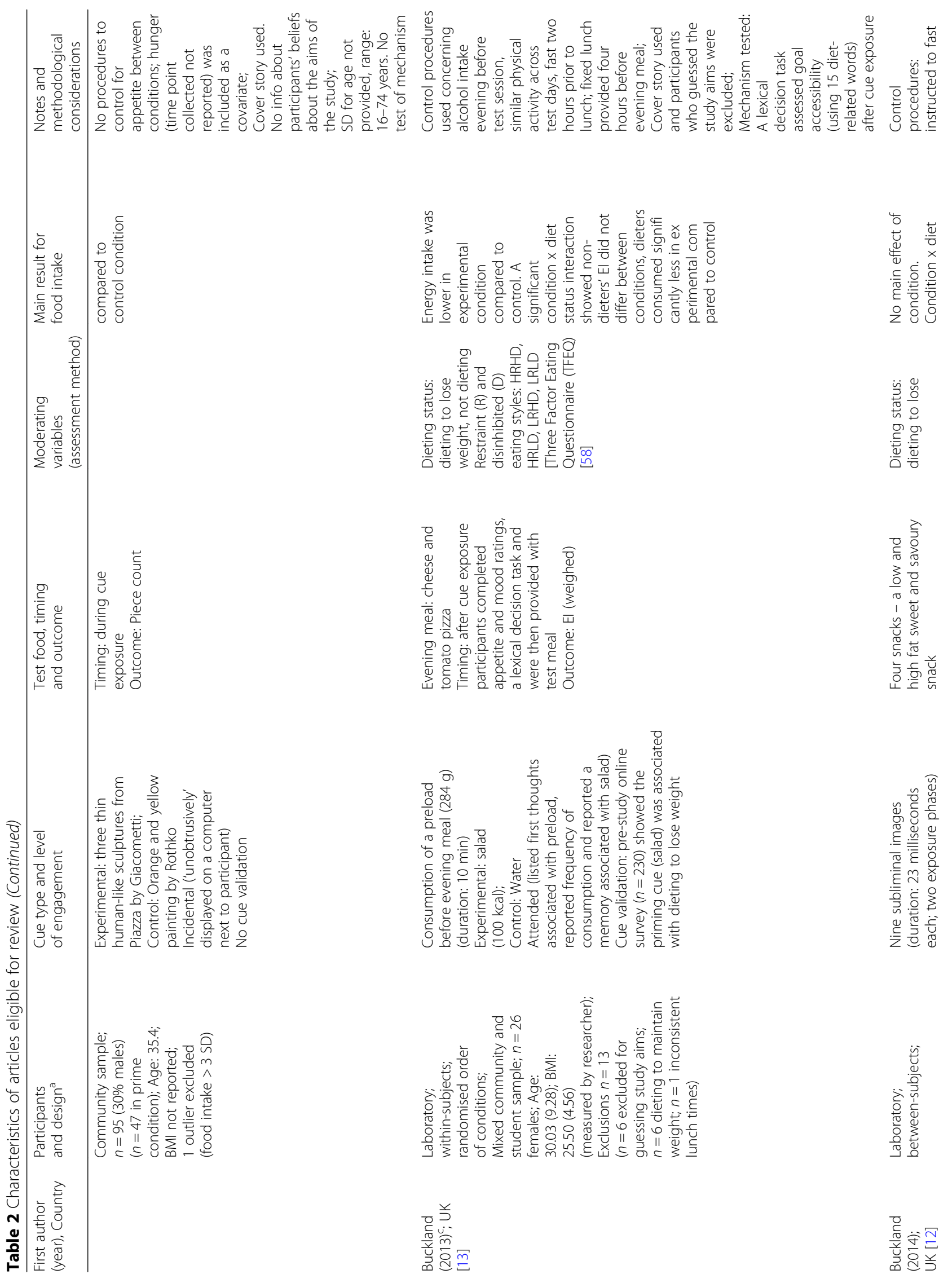




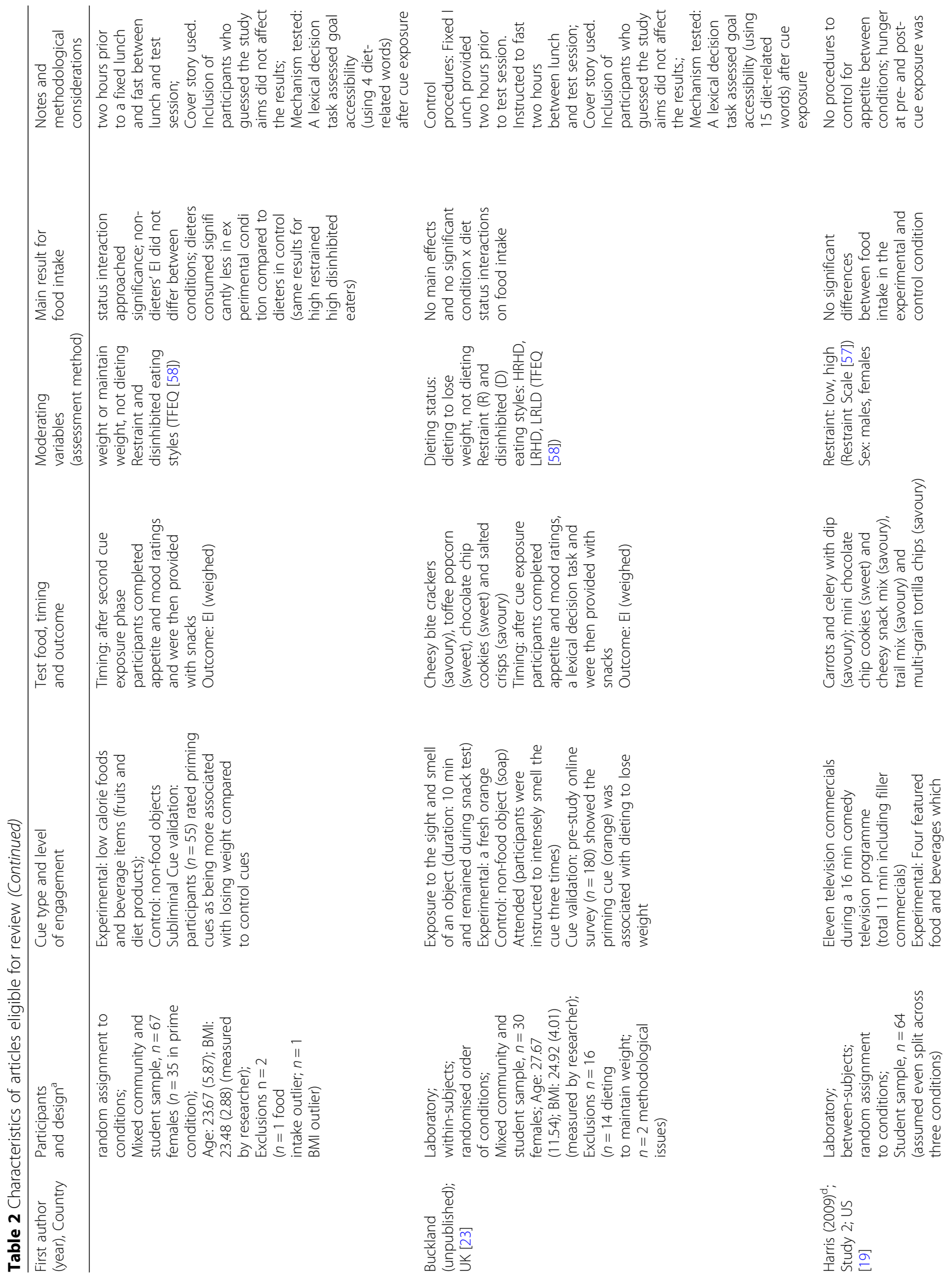




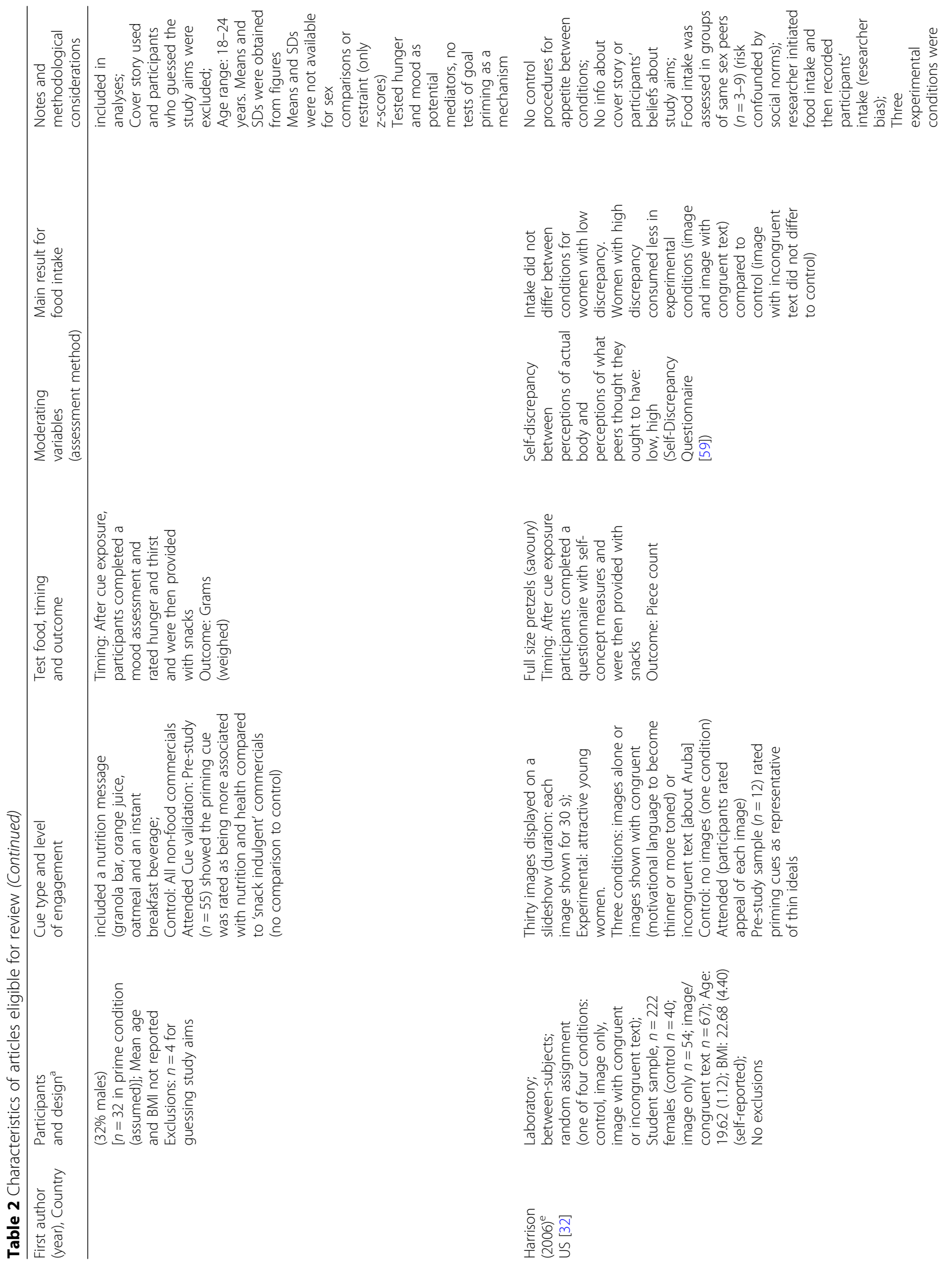




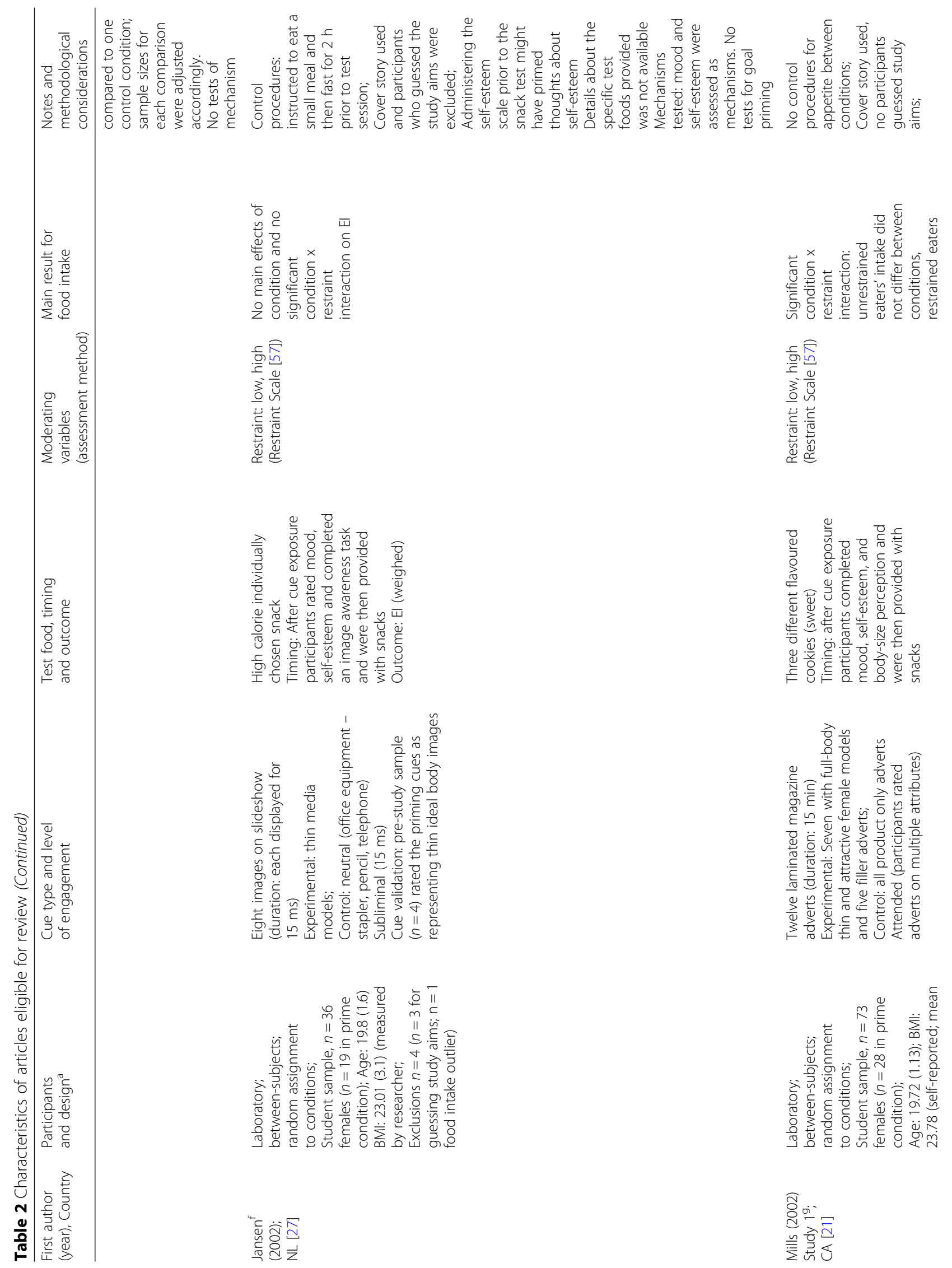




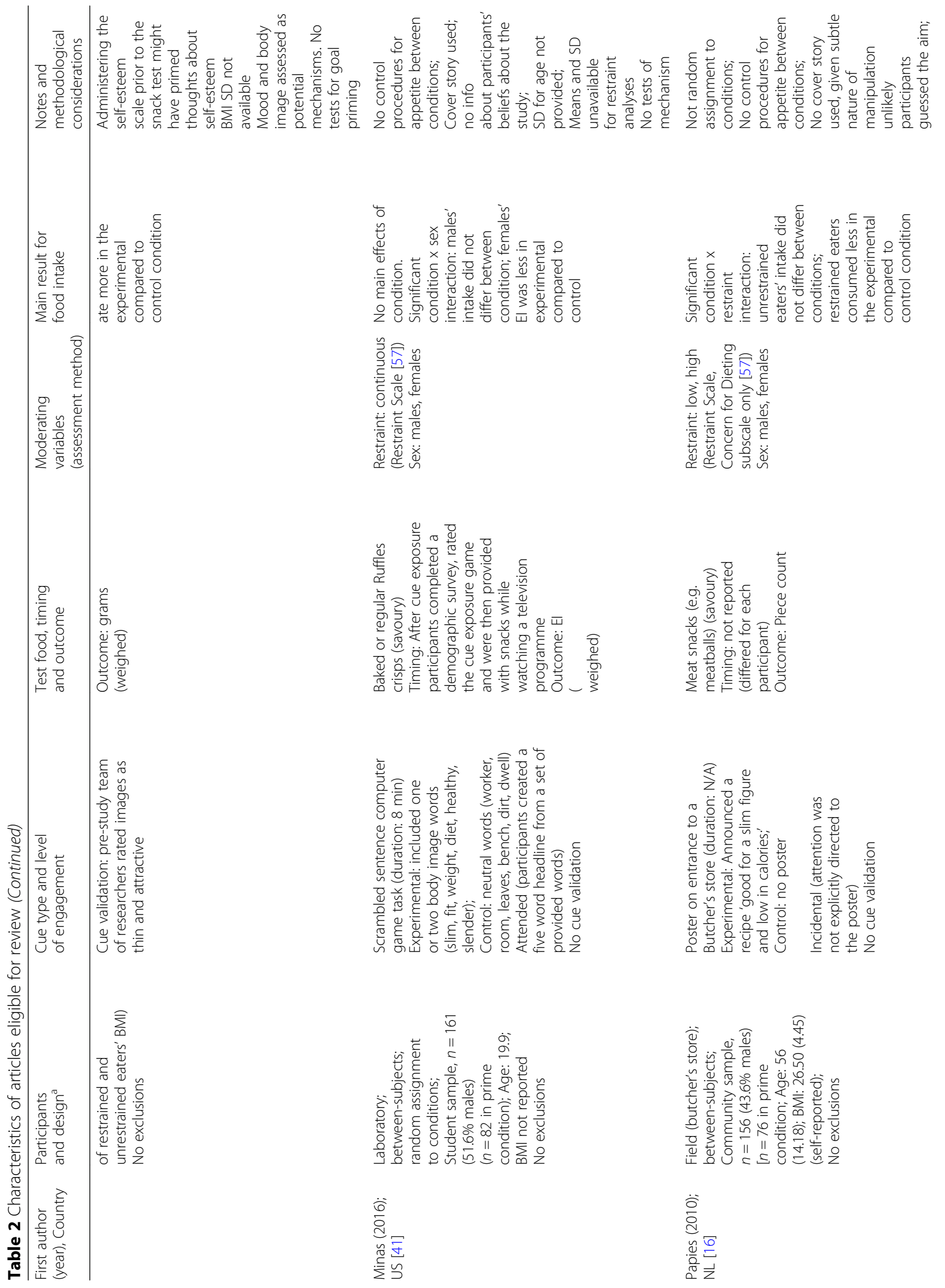




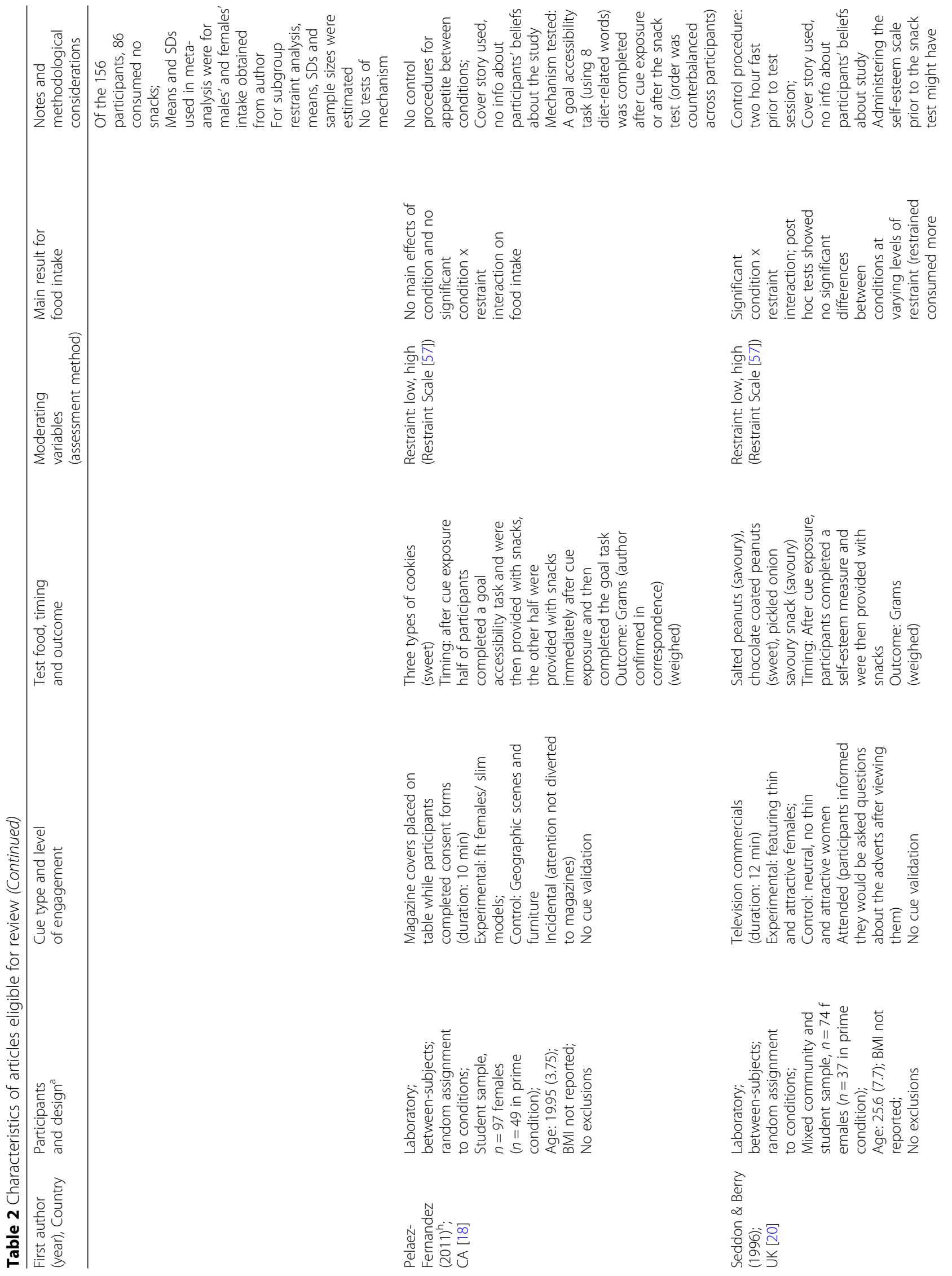




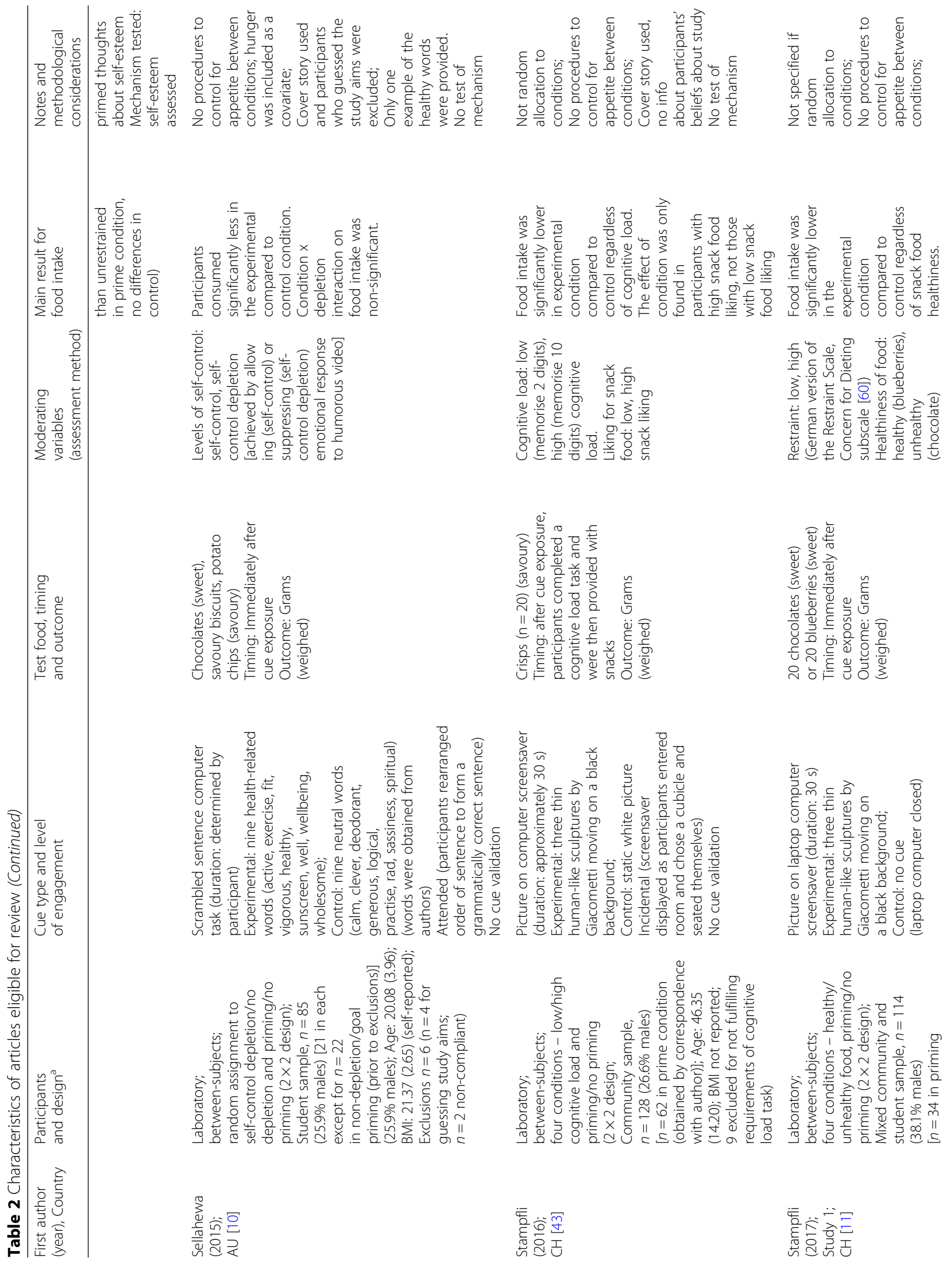




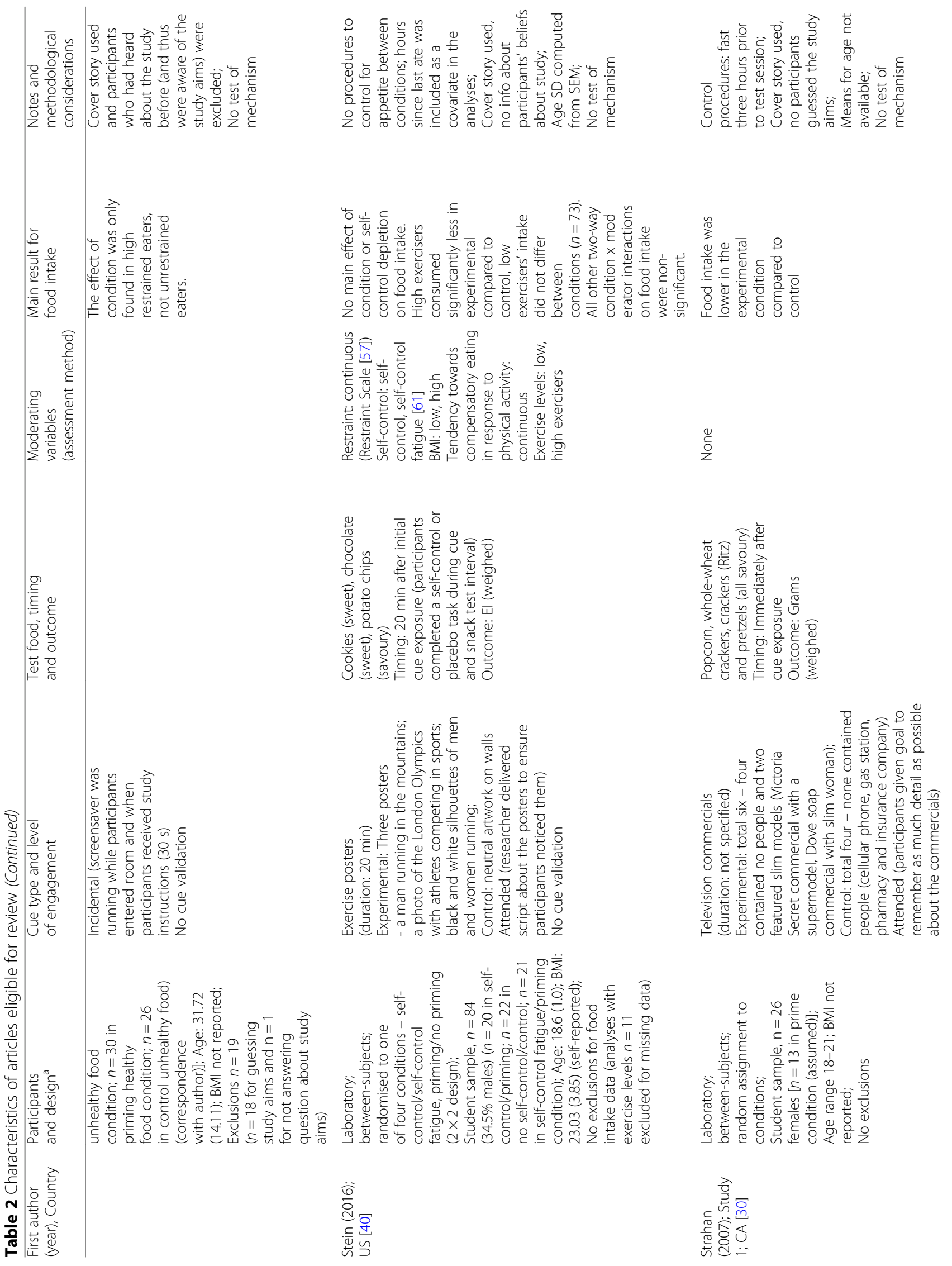




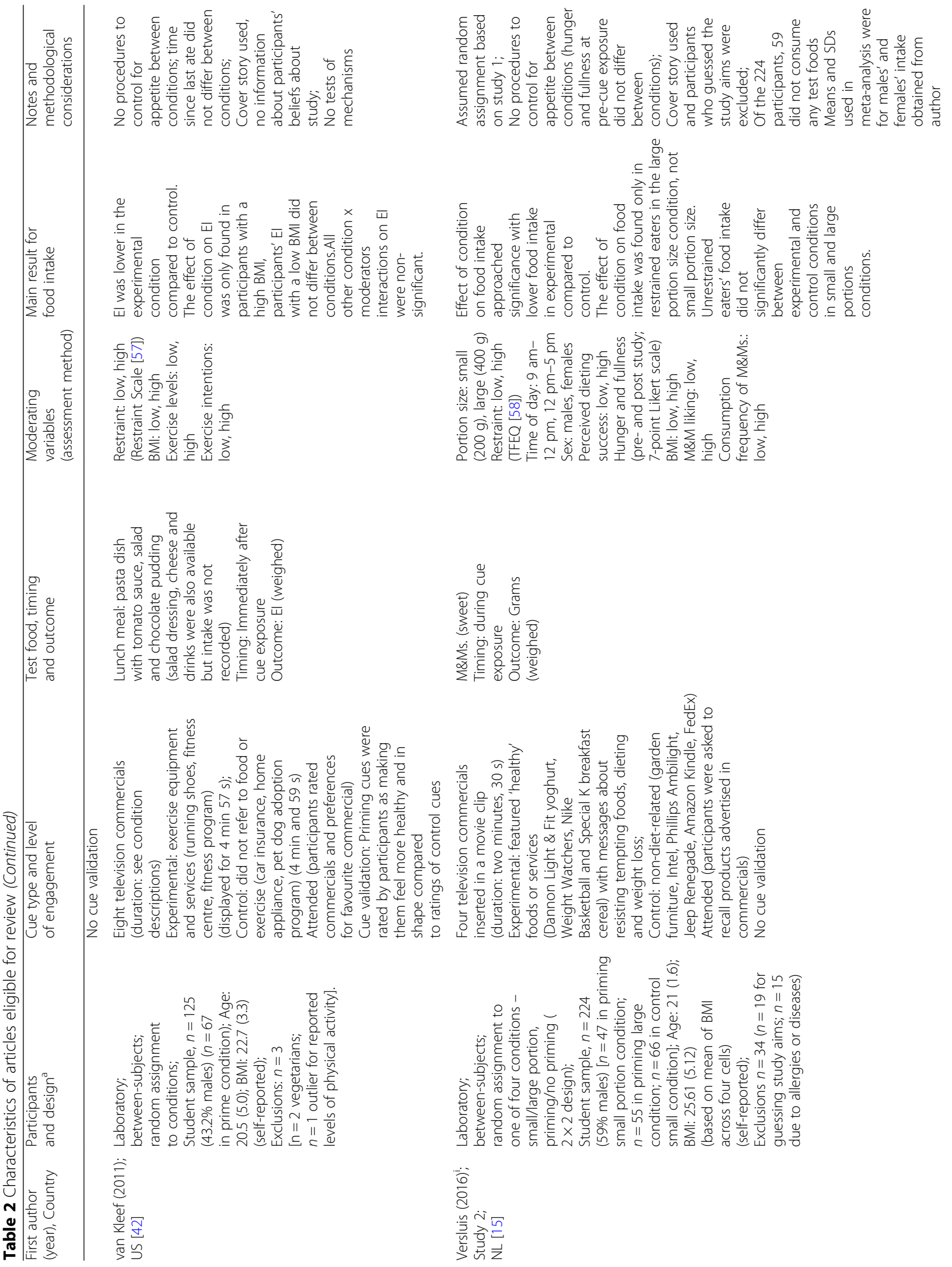




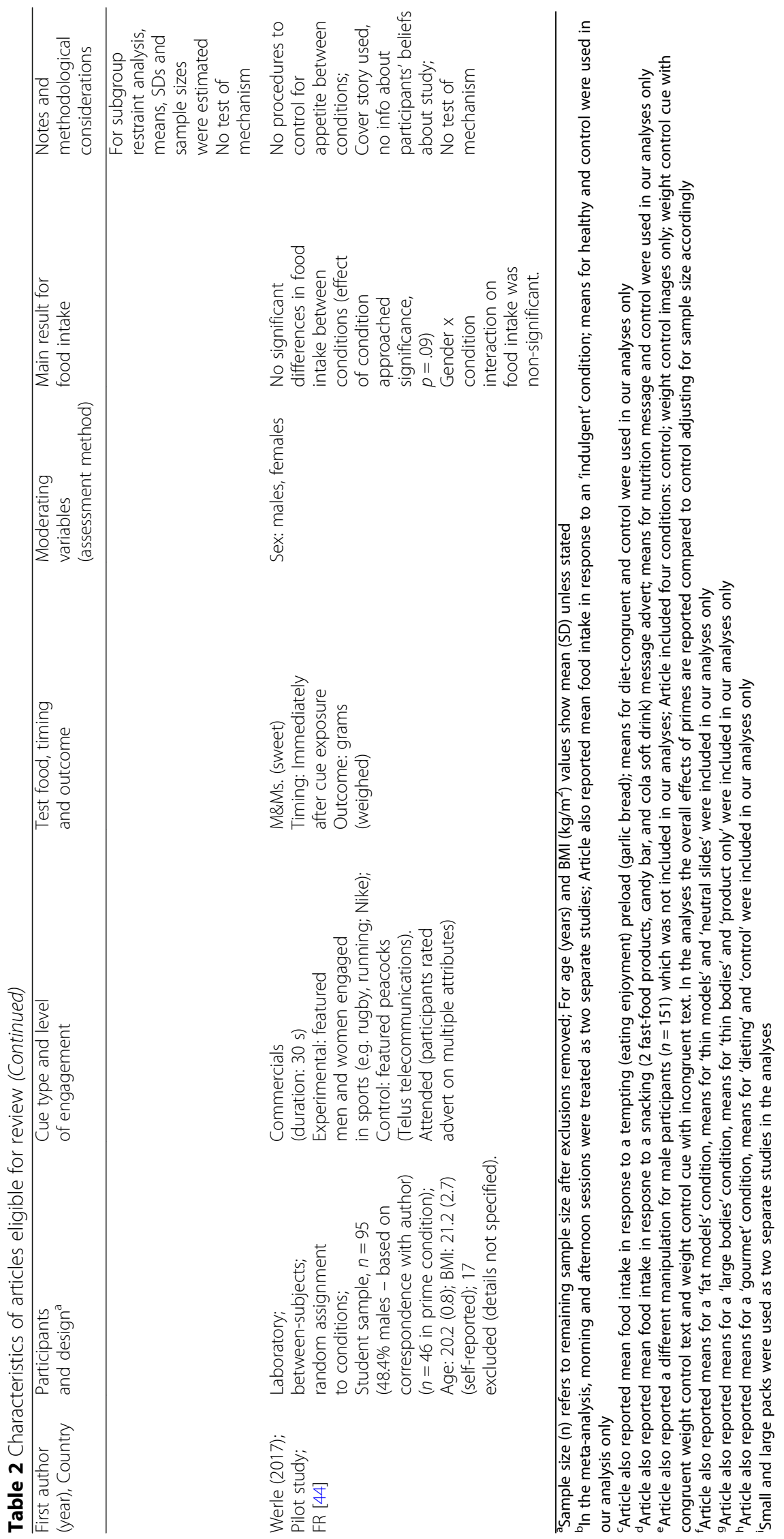


studies used student samples $[10,14,15,18,19,21,22$, $26-30,32,40-42,44]$, three used non-student samples [9, $16,43]$ and five used a combination of student and non-student samples [11-13, 20, 23]. Mean age was 24.8 \pm SD 9.5 years (median 20.3; range $18.6-56.0$ years) (mean age unavailable for two studies $[19,30])$. Mean BMI from available studies $(n=17[10,12,13,15,16,21-23,26-29$, $32,40,42,44]$ ) was $23.4 \pm \mathrm{SD} 1.5 \mathrm{~kg} / \mathrm{m}^{2}$ (median 23.0; range $21.2-26.5 \mathrm{~kg} / \mathrm{m}^{2}$ ). This was based on nine studies where participants' self-reported BMI $[10,15,16,21,29$, $32,40,42,44]$ and six where BMI was objectively measured by the researcher [12, 13, 22, 23, 27, 28]. Methods for obtaining BMI were not specified in two studies [26].

\section{Other study information}

All studies examined the effect of cues on short term food intake; however, there were variations in the interval between cue exposure and assessment of food intake. Thirteen studies assessed food intake either during cue exposure $(n=3[9,15,29])$ or immediately after cue exposure $(n=10[10-12,14,19,26,30,42,44])$, including those that also administered appetite ratings after cue exposure. For one study this was after a second exposure phase to counteract a lexical decision task [12]. In one study timing differed for each participant [16] and in another study a lexical decision task was administered after cue exposure for half of the participants while food intake of the other half was assessed immediately after cue exposure [18]. The remaining 11 studies administered tasks in between cue exposure and food intake which consisted of a lexical decision task [13, 23, 28], cognitive load [43] and self-control task [40], rating the cue exposure task and completing a demographic questionnaire [41], a self-concept questionnaire [32], a filler memory task implicit mood task and weight satisfaction [22], a self-esteem task only ${ }^{2}$ or with either a mood and image forced choice recognition task [27] or a mood and body size perception task [21]. Based on the questionnaires or tasks used, the four studies using tasks to assess mood, body satisfaction or self-esteem were classified in the meta-analysis as studies inducing negative body image or mood.

The majority of studies assessed snack intake; except for two which examined either lunch [42] or evening meal intake [13]. Of the studies providing snack foods, nine provided a sweet food: cookies [18, 21], M\&Ms. $[14,15,22,44]$, chocolate [9], raisins [26] and chocolate or blueberries [11]; five studies provided savoury snacks: pretzels [32], crisps [41, 43], crackers and pretzels [30] and meat samples [16]. Nine provided a selection of sweet and savoury foods $[10,12,19,20,23,26,28,29$, 40]. One study used a high calorie food that had been individually selected [27]. Twelve studies reported gram intake $[10,11,15,18-22,28,30,43,44] ; 10$ reported energy intake $[12,13,23,26,27,29,40-42]$; three reported piece count $[9,16,32]$ and one reported intake in ounces [14]. Most studies $(n=21)$ examined at least one moderating variable in response to cue exposure (see Table 2).

A range of weight control cues were used across studies (see Table 2). Eleven studies used thin models $[9,11$, $18,20-22,27,28,30,32,43]$, five used low calorie foods $[12,13,15,19,23]$, five used exercise cues $[26,40,42$, 44], three used a combination of healthy, exercise [10] and body weight or shape cues (e.g. word thin) [14, 41], one used a weight loss television programme [29] and one used a poster that referred to a low calorie recipe and slim fig. [16]. In most studies, participants attended to the cue $(n=18[10,13-15,19-23,26,28-30,32,40-$ 42, 44]). To engage attention, participants were either asked to rate the cue on various attributes (e.g. if presented as an advert or image) [21, 26, 32, 42, 44], encode the cue for subsequent recall $[15,20,22,28,30]$, eat or smell and handle the cue $[13,23]$, form sentences, create sentences or complete a word search task containing cue-relevant words $[10,14,41]$, watch a television programme containing cues $[19,29]$ or the researcher directed participants' attention to the cue [40]. Five studies used incidental exposure (achieved with slim figures on a computer screensaver $[9,11,43]$, having magazines that featured slim models in the testing rooms [18] and a poster on the window of a butcher's store [16]) and three used subliminal exposure (15-23 millisecond exposure to exercise words [26] and images of slim models [27] or low calorie food and beverages [12]). In eight studies the weight control cues were selected based on either pre-tests which validated that the cues were associated with dieting to lose weight $[13,23]$ or health and nutrition [19]; others validated body images as being slim and attractive as rated by either pre-study samples $[27,32]$ or researchers [21]; and other studies obtained ratings from the study participants that the cues were associated with dieting to lose weight [12] or made them feel 'healthy' and 'in shape' [42].

In terms of explaining the effects of exposure to weight control cues on food intake, seven studies assessed potential mechanisms; four studies administered tasks to assess the accessibility of diet-related goals (goal priming) [12, $13,18,23]$ and three assessed self-esteem [20, 27], mood $[21,27]$ or body size perception [21] as potential mechanisms for cues influencing food intake.

\section{Meta-analysis}

There was a trivial overall mean effect size of cue exposure in reducing food intake (ES: $-0.149,95 \%$ CI: -0.271 to $-0.027 ; n=31$; Fig. 2), which was statistically significant from zero $(p=0.017)$. Heterogeneity among the studies was moderate $\left(\mathrm{I}^{2}=56.88 \%\right)$. Sensitivity analysis based on the one-study-removed procedure did not 


$\begin{array}{lccc}\text { Study } & \text { Total N } & \text { Hedges'g } & p \text {-value } \\ \text { Albarracin (2009); Study 1 } & 53 & 0.546 & 0.048 \\ \text { Albarracin (2009); Study 2 } & 51 & 0.589 & 0.037 \\ \text { Boland (2013); Study 2, Afternoon } & 75 & -0.288 & 0.211 \\ \text { Boland (2013); Study 2, Morning } & 74 & 0.509 & 0.029 \\ \text { Bourn (2015) } & 99 & -0.339 & 0.092 \\ \text { Boyce (2013) } & 100 & 0.341 & 0.088 \\ \text { Brunner (2012); Study 1 } & 95 & -0.433 & 0.036 \\ \text { Buckland (2013) } & 26 & -0.619 & 0.000 \\ \text { Buckland (2014) } & 67 & -0.270 & 0.268 \\ \text { Buckland (unpublished) } & 30 & -0.060 & 0.744 \\ \text { Harris (2009); Study 2 } & 64 & -0.258 & 0.298 \\ \text { Harrison (2006); Image/congruent text } & 79 & -0.394 & 0.204 \\ \text { Harrison (2006); Image/incongruent text } & 73 & 0.006 & 0.984 \\ \text { Harrison (2006); Image/no text } & 66 & -0.366 & 0.243 \\ \text { Jansen (2002) } & 36 & -0.106 & 0.741 \\ \text { Mills (2002); Study 1 } & 73 & 0.164 & 0.490 \\ \text { Minas (2016) } & 161 & -0.147 & 0.355 \\ \text { Papies (2010) } & 156 & -0.008 & 0.958 \\ \text { Pelaez-Fernandez (2011) } & 97 & 0.417 & 0.039 \\ \text { Seddon(1996) } & 74 & -0.074 & 0.750 \\ \text { Sellahewa (2015); Depletion } & 42 & -0.637 & 0.040 \\ \text { Sellahewa (2015); Non-depletion } & 44 & -0.277 & 0.352 \\ \text { Stampfli (2016); Study 1 } & 128 & -0.383 & 0.031 \\ \text { Stampfli (2017); Stalf } & 114 & -0.389 & 0.040 \\ \text { Stein (2016); Self-control fatigue } & 42 & -0.246 & 0.418 \\ \text { Stein (2016); Self-control placebo } & 42 & -0.275 & 0.367 \\ \text { Strahan (2007); Study 1 } & 26 & -0.911 & 0.023 \\ \text { van Kleef (2011) } & 124 & -0.536 & 0.003 \\ \text { Versluis (2016); Study 2, Large pack } & 111 & -0.411 & 0.031 \\ \text { Versluis (2016); Study 2, Small pack } & 113 & -0.155 & 0.416 \\ \text { Werle (2017); Pilot study } & 95 & 0.178 & 0.382 \\ \text { Overall } & & -0.149 & \mathbf{0 . 0 1 7} \\ & & & \end{array}$

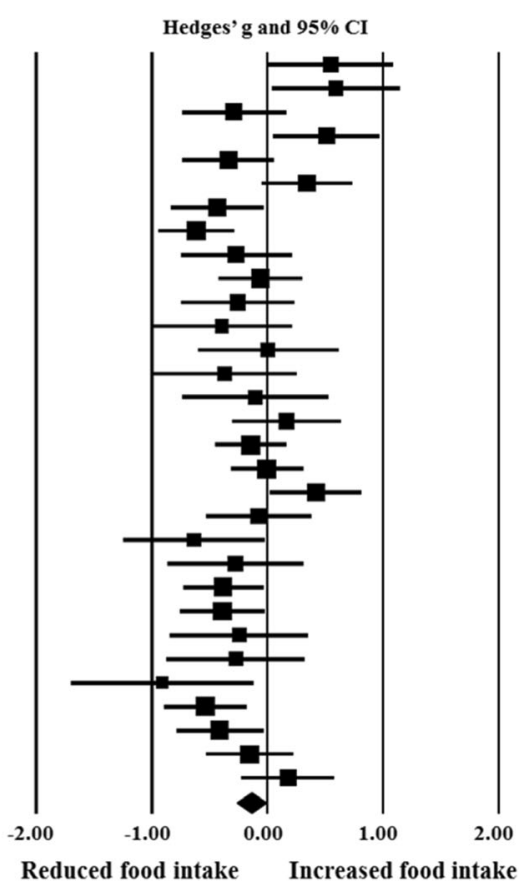

Fig. 2 Forest plot of comparisons between exposure to weight control and control cues on food intake

reveal any major impact of a single study on the overall effect size.

\section{Planned moderator analysis: Cue type and level of engagement}

Results from the moderator analyses are presented in Table 3. Cue type and level of engagement did not significantly impact the variation in the effect of cue exposure on food intake. However, there were effect sizes significantly different from zero favouring a reduction in food intake when cues were low calorie foods or thin models, and when cues were attended to. Important to note, there was low variability across studies using low calorie foods $\left(\mathrm{I}^{2}=20.47 \%\right)$.

\section{Planned subgroup analysis: Weight control goals}

Subgroup analysis on data reported in 13 studies (contributing 26 effect sizes) showed no significant variation in the effect of cue exposure on food intake between groups with weak or strong weight control goals (Table 3). However, as heterogeneity was moderate in the strong weight control goal group $\left(\mathrm{I}^{2}=65.11 \%\right)$ [low heterogeneity in the weak weight control goal group $\left.\left(\mathrm{I}^{2}=0.00 \%\right)\right]$ and there was concern that some studies were confounded with negative affect after cue exposure, exploratory subgroup analysis was conducted with these studies removed [20, $21,27]$. Upon removal, the analysis showed significant variation in the impact of cue exposure between subgroups. For participants with strong weight control goals, cue exposure decreased food intake compared to control with a small-to-moderate effect size, which differed significantly from zero (heterogeneity slightly decreased: $\mathrm{I}^{2}=56.84 \%$ ), whereas for participants with weak weight control goals, the effect of cue exposure on food intake was trivial and non-significant. In two of these studies (contributing 3 effect sizes) $[15,16]$ means and standard deviations had to be estimated by the research team (see Table 2). Removal of these studies did reduce the effect of the moderator to non-significant $(p=0.159)$; however, the effect size for participants with strong weight control goals remained significant and small-to-moderate (ES: -0.378 , 95\% CI: -0.733 to $-0.023 ; p=0.037, n=7$ ).

\section{Exploratory analyses}

Table 3 shows the moderators examined. The only moderator with a significant impact on the variation of the effect of cue exposure on food intake was whether appetite had been controlled for. Food intake significantly decreased after exposure to weight control cues relative to control and with small-to-moderate effects in studies that controlled for appetite (either using study procedures or including appetite ratings in the analysis). The impact of sex on the effect of cue exposure on food intake approached significance $(p=.06)$, with food intake significantly decreasing after exposure to weight control cues with a small effect size in females.

It is also of interest to note that, within the other moderators, significant effect sizes favouring a reduction in food intake with cue exposure were apparent with validated cues, in mixed student-community samples, in 
Table 3 Subgroup and moderator analyses

\begin{tabular}{|c|c|c|c|}
\hline Moderator variables & Subgroup level & $p$ for between subgroup heterogeneity & Effect size (Hedges' g) $(95 \% \text { Cl) })^{i}$ \\
\hline \multicolumn{4}{|l|}{ Subgroups } \\
\hline \multirow[t]{2}{*}{ WC goals } & Weak WC goals $(n=13)$ & 0.351 & $-0.071(-0.329,0.187)$ \\
\hline & Strong WC goals $(n=13)$ & & $-0.248(-0.517,0.020)$ \\
\hline \multirow{2}{*}{$\begin{array}{l}\text { WC goals } \\
\text { (removing negative affectii) }\end{array}$} & Weak WC goals $(n=10)$ & 0.020 & $0.014(-0.249,0.278)$ \\
\hline & Strong WC goals $(n=10)$ & & $-0.440(-0.718,-0.163)^{* *}$ \\
\hline \multirow[t]{2}{*}{ Sex } & Females $(n=5)$ & 0.056 & $-0.305(-0.574,-0.036)^{*}$ \\
\hline & Males $(n=5)$ & & $0.057(-0.200,0.314)$ \\
\hline \multicolumn{4}{|l|}{ Categorical moderators } \\
\hline \multirow[t]{6}{*}{ Cue type } & Exercise $(n=6)$ & 0.309 & $0.018(-0.268,0.303)$ \\
\hline & Low kcal foods $(n=6)$ & & $-0.302(-0.560,-0.044)^{*}$ \\
\hline & Mixed $(n=5)$ & & $-0.098(-0.403,0.206)$ \\
\hline & Thin models $(n=9)$ & & $-0.249(-0.476,-0.022)^{*}$ \\
\hline & Thin models - negative $(n=4)$ & & $0.105(-0.238,0.448)$ \\
\hline & TV show $(n=1)$ & & $-0.339(-0.968,0.290)$ \\
\hline \multirow[t]{3}{*}{ Cue engagement } & Attended $(n=23)$ & 0.616 & $-0.169(-0.316,-0.023)^{*}$ \\
\hline & Incidental $(n=5)$ & & $-0.160(-0.444,0.124)$ \\
\hline & Subliminal $(n=3)$ & & $0.061(-0.375,0.498)$ \\
\hline \multirow[t]{2}{*}{ Cue validated } & Not validated $(n=21)$ & 0.213 & $-0.098(-0.242,0.046)$ \\
\hline & Validated $(n=10)$ & & $-0.263(-0.478,-0.047)^{*}$ \\
\hline \multirow[t]{3}{*}{ Sample type } & General community $(n=3)$ & 0.363 & $-0.263(-0.616,0.090)$ \\
\hline & Mixed $(n=5)$ & & $-0.295(-0.579,-0.010)^{*}$ \\
\hline & Students $(n=23)$ & & $-0.091(-0.236,0.055)$ \\
\hline \multirow[t]{2}{*}{ Sex } & Females $(n=13)$ & 0.884 & $-0.137(-0.333,0.059)$ \\
\hline & Mixed $(n=18)$ & & $-0.156(-0.316,0.004)$ \\
\hline \multirow[t]{5}{*}{ Cue-food intake intervaliii } & During/immediately $(n=16)$ & 0.091 & $-0.188(-0.347,-0.030)^{*}$ \\
\hline & After tasks $(n=9)$ & & $-0.284(-0.496,-0.072)^{* *}$ \\
\hline & After negative tasks $(n=4)$ & & $0.107(-0.216,0.431)$ \\
\hline & Counterbalanced $(n=1)$ & & $0.417(-0.173,1.006)$ \\
\hline & Varied $(n=1)$ & & $-0.008(-0.545,0.528)$ \\
\hline \multirow[t]{4}{*}{ Snack type } & Not reported $(n=1)$ & 0.132 & $-0.106(-0.894,0.681)$ \\
\hline & Savoury $(n=8)$ & & $-0.316(-0.549,-0.083)^{* *}$ \\
\hline & Sweet $(n=11)$ & & $0.023(-0.167,0.213)$ \\
\hline & Sweet and savoury $(n=11)$ & & $-0.221(-0.426,-0.017)^{*}$ \\
\hline \multirow[t]{5}{*}{ Outcome } & Energy intake $(n=11)$ & 0.849 & $-0.167(-0.380,0.046)$ \\
\hline & Grams $(n=12)$ & & $-0.136(-0.338,0.067)$ \\
\hline & Grams z-scores $(n=1)$ & & $-0.258(-0.984,0.467)$ \\
\hline & Ounces $(n=2)$ & & $0.108(-0.390,0.606)$ \\
\hline & Piece count $(n=5)$ & & $-0.227(-0.554,0.101)$ \\
\hline \multirow[t]{2}{*}{ Controlled appetite } & No control $(n=15)$ & 0.016 & $-0.008(-0.169,0.154)$ \\
\hline & Controlled for $(n=16)$ & & $-0.289(-0.451,-0.128)^{* * *}$ \\
\hline \multirow[t]{2}{*}{ Theoretical approach ${ }^{\vee}$} & Body image $(n=9)$ & 0.427 & $-0.125(-0.350,0.099)$ \\
\hline & Goal priming $(n=19)$ & & $-0.231(-0.367,-0.096)^{* *}$ \\
\hline
\end{tabular}

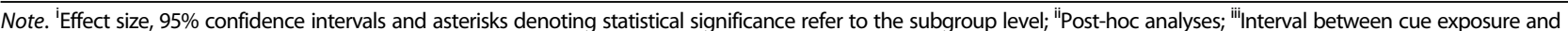
assessment of food intake; ${ }^{\mathrm{iv}}$ Based on either study procedures or including reported appetite in analyses; ${ }^{\mathrm{V}}$ Two studies using motor priming were not included in the moderator analysis as both were from one article [26], another using vicarious goal fulfilment was also not included [46]. ${ }^{*} p<.05 ;{ }^{* *} p<.01 ;{ }^{* * *} p<.001$ at the subgroup level 
studies that assessed food intake during or immediately after cue exposure or after tasks that did not induce negative affect, savoury snacks, combined sweet and savoury snacks, and in studies that used a goal priming theoretical approach.

\section{Risk of bias}

A summary for risk of bias is shown in Fig. 3. For 'sequence generation', all studies were rated at high risk; two did not randomly assign participants to conditions $[16,43]$, three studies did not specify whether randomisation had been used or randomisation had to be assumed based on a previous study reported in the article $[9,11,15]$; all remaining studies specified random allocation to conditions or random order of conditions (within-subject designs [13, 23]) but no studies reported randomisation methods used and as such were rated at high risk.

No studies specified whether allocation concealment had been used. As such all studies were rated as unclear risk, except for those using a repeated measures design (low risk) $[13,23]$ and a study conducted by one of the current authors who confirmed allocation concealment had not been used [12]. For the criteria 'blinding of participants and personnel', twelve studies were rated at high risk for either not providing information about a cover story or providing a cover story but not reporting whether participants believed the cover story $[9,18,20,26,29,32,40-44]$. All other studies were rated at low risk for blinding of participants and personnel. For blinding of outcome assesors, all studies were rated at high risk, except for two that were unclear $[19,34]$ and one that was rated as low risk [43]. For the criteria incomplete outcome data' four studies were considered at high risk for excluding participants for reasons not given in the exclusion criteria [22, 28, 42, 43]. For the criteria 'selective outcomes', five studies were considered to be at high risk; two did not report means and standard deviations for non-significant results (planned analyses) $[40,41]$, two studies reported unplanned analyses [11, 43] and one study had conducted two additional separate conditions but due to non-significant findings merged the data from these conditions with the weight control and control conditions [42]. For 'other bias', eighteen studies were considered at high risk for a variety of confounding variables (some studies had multiple confounding variables): using piece count to assess intake ( $n=5[9,16,26$, 32], not using procedures to control for subjective appetite (e.g. fasting period, fixed meals or including subjective appetite ratings or duration since last ate as a covariate, $n=11[11,14,16,18,21,26,29,32,41,43])$; assessing intake in the presence of social others $(n=3[16,32,42])$, administering psychometric scales prior to assessing food intake (e.g. weight satisfaction, self-esteem, body size perception; $n=4[20,21,27,28])$, providing a restricted portion of food $(\mathrm{n}=4[9,11,26,43])$ and not measuring all foods provided $(n=1$ [42]). Two studies were rated as unclear for either not specifying the control procedure [40] (e.g. for the experimental condition the researcher diverted participants' attention to cues, no information provided about the procedure for the control condition) or not specifying whether food intake was assessed individually or in the presence of social others [19]. The remaining six studies were rated at low risk for 'other bias' $[10,12,13,22,23,30]$.

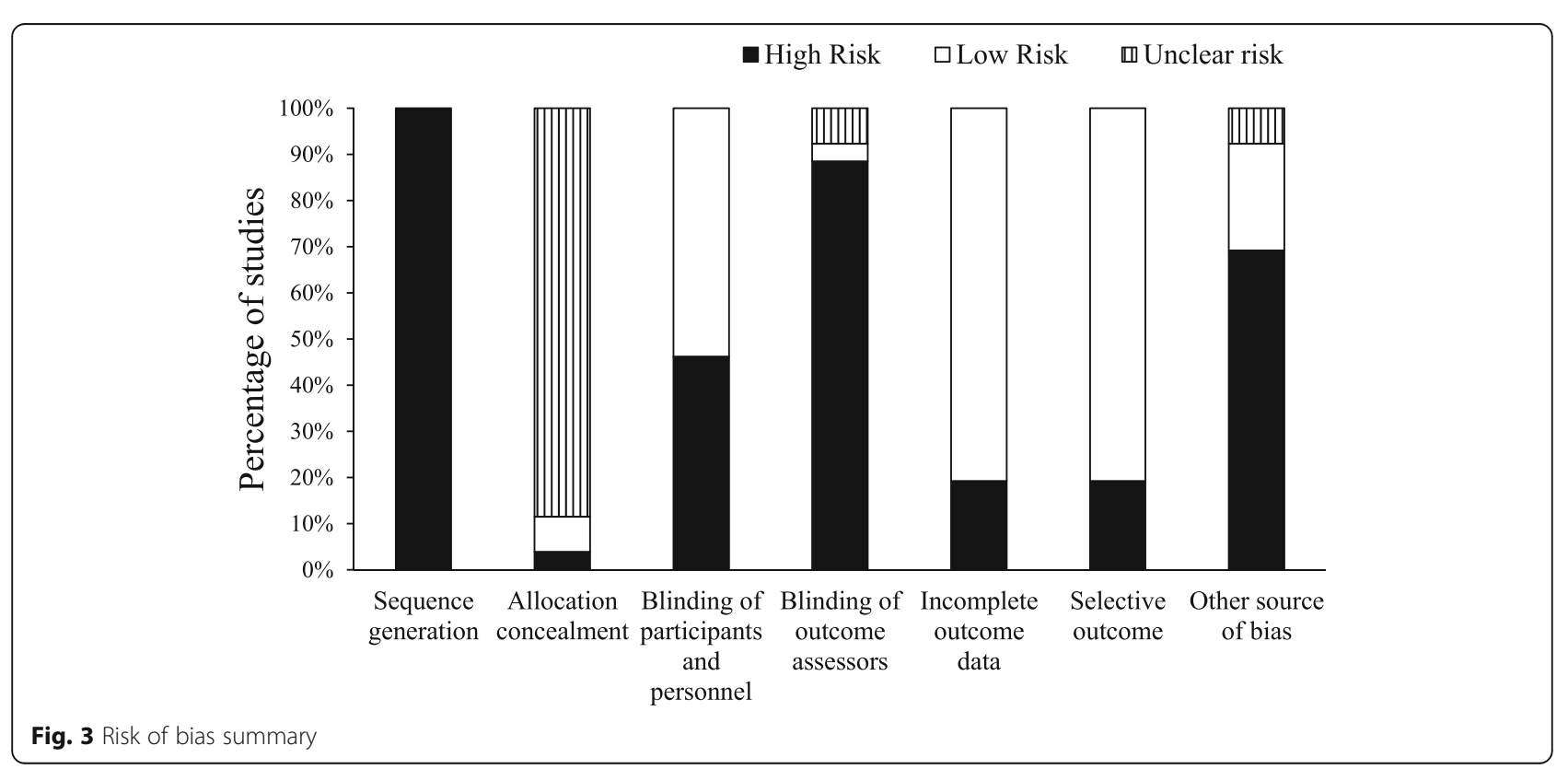




\section{Publication bias}

Inspection of the funnel plot (Additional file 3) showed a slight shift to the left of the mean, suggesting some presence of publication bias. Egger's regression intercept revealed little evidence of publication bias (intercept: 0.33 , 95\% CI: -2.15 to $2.81, p=0.788$ ); however, the trim-and-fill analysis revealed evidence of four missing studies reporting increased food intake in response to cue exposure to bring symmetry to the right of the mean. These studies, would have to have an ES $\geq 0.4$, to moderate the ES to -0.080 ( $95 \%$ CI -0.208 to 0.047 ), negating its significance.

\section{Discussion}

This systematic review and meta-analysis assessed the effect of exposure to weight control cues on food intake. Results from the meta-analysis, which combined 24 articles (25 studies) and contributed 31 effect sizes, suggest that in general, exposure to weight control cues has a trivial effect to reduce food intake compared to control cues. The magnitude of this effect was increased in individuals with strong weight control goals (identified as being either dieters, restrained eaters or those with high-self discrepancy). Cue type and level of engagement with cues did not moderate the effect. However, the effect sizes were more consistent (as indicated by low heterogeneity) and significant when low calorie foods were used as the weight control cue. The effect sizes were also significant for thin models (with no negative affect) and when participants attended to the weight control cues. Studies using incidental and subliminal cue exposure did not significantly affect food intake.

To our knowledge this is the first systematic review and meta-analysis examining the effect of weight control cues on food intake. The findings support narrative reviews that weight control cues can reduce food intake, especially in individuals with strong weight control goals $[8,17]$. This finding is also in accordance with the Goal Conflict Theory which states that cues will elicit a greater response in those with relevant goals [45]. In the current meta-analysis, this selective response to weight control cues (based on the strength of weight control goals) suggests the results might be due to goal priming. However, further investigation is required to confirm goal priming as a mechanism. Previous research has shown that exposure to weight control cues increases accessibility of weight control goals [46]. In this meta-analysis, there were insufficient studies which tested goal priming as a mechanism to be able to draw clear conclusions. As such, it is recommended that studies investigating the effects of weight control cues on food intake incorporate tests to identify possible goal priming mechanisms. One of the reasons why few studies incorporated tests of goal priming mechanisms may be because the tests themselves can disrupt or confound the effects of cue exposure on subsequent food intake. Thus, researchers need to identify effective methods to overcome this issue such as counterbalancing the order that the mechanism and food intake is assessed [18], repeating cue exposure after testing the mechanism $[12,23]$ or devising alternative tasks based on the principles of goal priming [45].

The Goal Conflict Theory proposes that weight control cues will have selective effects on those with strong weight control goals because such individuals hold conflicting weight control and eating enjoyment goals [8]. As both eating enjoyment and weight control goals cannot be active at the same time, activation of one will lead to inhibition of the other. For example, in food-tempting settings, the eating enjoyment goal becomes more prominent and the weight control goal is momentarily inhibited, resulting in behaviour consistent with eating enjoyment goals. In contrast, weight control cues reinstate the weight control goal and facilitate controlled food intake in tempting food environments. Individuals with weak weight control goals do not experience such conflict and therefore their behaviour is less determined by environmental cues. Thus, the selective response to weight control cues found in this meta-analysis is consistent with the Goal Conflict Theory.

Yet, caution is needed when interpreting the finding that the strength of weight control goals moderated the effect of weight control cues on food intake, as this effect was only found after removing the studies which induced negative affect after cue exposure (by administering scale assessing weight satisfaction, self-esteem, body size discrepancy and negative mood scales). These differences in methodologies might have partly explained the moderate heterogeneity observed and justified removing these studies. Indeed, the difference that removing these studies made to the overall effect is consistent with a recent review which suggested that weight control cues will be most effective if they are associated with positive affect [17]. It is possible that studies that induce awareness of body image after cue exposure activate alternative processes which undermine the effects of cue exposure. However, it should be acknowledged that there were a number of studies which examined weight control goals as moderators but the means and standard deviations could not be obtained [11, 19, 22, 40-42]. Thus, further research comparing the effect of weight control cues in individuals with strong and weak weight control goals is needed. Direct comparisons between exposure to weight control cues only and exposure to weight control cues with tasks that increase awareness of body image are also needed. Furthermore, this meta-analysis assessed the impact of weight control cues as moderated by weak and strong weight control 
goals. Yet, very few studies included samples who were engaged in an active weight control attempt [12, 13, 23] most used measures of restrained eating to determine weight control goals $[11,15,16,18,19,40-42]$. It has been argued that restrained eating assesses the tendency to watch what one eats rather than engaging in weight control strategies per se [47]. Thus, the effect of weight control cues on food intake need to be evidenced in more samples who are actively engaged in weight control attempts. It is also important to note that the grouping of low and high weight control goals in this meta-analysis was an exploratory analysis.

It is interesting that level of engagement with the cue did not significantly moderate the effects of weight control cues on food intake. However, this may be an issue of power as only a small number of studies investigated incidental and subliminal cues. It is important to note that attending to cue exposure did have a significant effect in reducing food intake and this finding is consistent with literature on mindfulness. Mindful eating involves focusing on the sensational experience of eating and food-related thoughts and it has been shown to reduce cravings [16, 48] and food intake [49]. This meta-analysis suggests that focusing on a weight control cue can also decrease food intake in those with strong weight control goals.

Controlling for appetite was another methodological difference between studies. Exploratory analyses showed effect sizes were larger in studies which controlled for appetite compared to those that did not. Using procedures to control for appetite (such as participants fasting for a given period of time or being provided with a fixed-caloric meal) reduces non-systematic variance in food intake and improves the quality of the research design. Although not able to test here, it is possible that appetite moderates the effect of cue exposure on food intake and therefore it is important to control for it. Based on this finding we would strongly recommend researchers adopt standardised procedures when conducting laboratory studies [24, 38]. Adoption of such procedures is also important as the quality assessment showed that most studies were rated as at high risk of bias (Additional file 2). This recommendation is in line with a recent call for future laboratory eating behaviour studies to adopt more rigorous methods [50].

The current findings have important implications. While future studies are needed to confirm the durability of the effects of weight control on food intake (e.g. after repeated exposure), exposure to weight control cues has relevance for weight control attempts. Of course, it cannot be assumed that short term reductions in food intake will result in long term weight changes $[51,52]$. As such, the impact of weight control cues on food intake and changes in body weight over time needs to be tested. Subsequent research could test the effects of incorporating weight control cues into a weight loss programme on changes in body weight. In today's technology-rich environment, weight control cues could be delivered via smart phone applications and used with ease and minimal cost [53].

Consideration of the limitations of the systematic review and meta-analysis is needed. To our knowledge, there are no validated databases of weight control cues and as such, the research team used their judgement about which cues qualified as being weight control cues. For instance, the selection criteria used did not include eating enjoyment cues as weight control cues (e.g. palatable food or overweight models [54]). However, it has been suggested that for some individuals, eating enjoyment cues themselves might activate weight control cognitions [55]. For example, individuals who report high levels of dieting success may have learned over time to associate eating enjoyment cues with weight control cognitions, meaning that weight control goals are activated in response to eating enjoyment cues [55]. As this may involve different processes to more 'prototypical' weight control cues, eating enjoyment cues were not included in the current meta-analysis. Importantly, this issue highlights that across studies there may be subjectivity in the definition and selection of cues used to activate weight control cognitions. It is possible that some studies may have used cues that the sample did not associate with weight control (even if the researchers assumed they did) and thus, this may have minimised the opportunity to observe effects of weight control cues in some studies. In support of this, the current findings showed that effects were only significant in studies that validated cues either before or during the study as being associated with weight control constructs (although not a significant moderator). Therefore, it will be valuable for future research to develop a validated database of weight control cues that report the extent to which a range of cues are associated with weight control and the extent to which these vary within and between sub-populations (for example, age, restrained eaters, types of dieters - successful versus less successful weight losers and maintainers). This will be a valuable resource for researchers to use when conducting goal priming studies.

The current findings are also limited to the data available. There were a number of studies which examined weight control goals $[11,19,22,40-42]$ or other moderators such as BMI [40, 42] and exercise levels [42] that were not included in the meta-analysis due to insufficient data being available. Additionally, the risk of bias assessment showed that due to methodological issues, most of the studies were rated as being at high risk of bias and as such the findings should be interpreted with caution. Moreover, in terms of public health applications, the 
current findings provide support that weight control cues can improve acute control over food intake in individuals with goals to lose weight. This support is based predominantly on laboratory-based findings and as such more studies in real world settings are needed before applying such strategies to public health initiatives. This is important because although only small-to-moderate effects were reported for individuals with strong weight control goals, when scaled up and integrated as part of a wider national-level strategy tackling overconsumption, such effects can have an important impact on the population [56]. However, weight control cues will likely to have no impact on individuals who do not have weight control goals, who might also be the target of public health behaviour change interventions. As such, the findings suggest that alternative methods are needed that consider individual motivations or goals.

\section{Conclusion}

Results from this systematic review and meta-analysis showed weight control cues can reduce food intake and more so in individuals with strong weight control goals. However, the effects of weight control cues in those with strong weight control goals were only apparent when studies increasing body image awareness (and thus negative affect) were removed, suggesting that to impact food intake weight control cues should be presented in the absence of negative affect. The mechanisms underlying this effect remain to be evidenced and further studies are required to confirm which types of cues and level of engagement are most effective.

\section{Endnotes}

${ }^{1}$ For instance, in three studies snacks were provided seven [14 (Study 1) confirmed in correspondence with author], fourteen [62] and twenty minutes [63] before cue exposure.

${ }^{2}$ Seddon and Berry (1996) and Mills, Polivy, Herman \& Tiggemann (2002) used The State Self-esteem Scale [64]; Jansen \& de Vries (2002) participants rated state depression and state satisfaction on visual analogue scales.

\section{Additional files}

Additional file 1: Electronic Supplementary Information Detailed search strategy (example database search). Description: keys terms used in the electronic database search. (DOCX $18 \mathrm{~kb}$ ).

Additional file 2: Risk of bias assessment. Description: Table showing risk of bias assessment for each study (DOCX $19 \mathrm{~kb}$ ).

Additional file 3: Risk of bias funnel plot. Description: Figure showing risk of bias funnel plot (DOCX $50 \mathrm{~kb}$ ).

\section{Acknowledgements}

We would like to thank Chandani Nekitsing, University of Leeds for her guidance conducting the meta-analysis.
Funding

This study was funded by a Cancer Research UK BUPA innovation grant.

\section{Availability of data and materials}

The datasets used and/or analysed during the current study are available from the corresponding author on reasonable request.

\section{Authors' contributions}

NB conceived the research aims, conducted the literature search, wrote the manuscript and had primary responsibility for the final content. NB and KB conducted full text screening and extracted and analysed the data.

All authors reviewed and approved the final manuscript.

Ethics approval and consent to participate

Not applicable.

\section{Consent for publication}

Not applicable.

\section{Competing interests}

The authors declare that they have no competing interests.

\section{Publisher's Note}

Springer Nature remains neutral with regard to jurisdictional claims in published maps and institutional affiliations.

\section{Author details}

'Department of Psychology, University of Sheffield, Cathedral Court, 1 Vicar Lane, Sheffield S1 2LT, England. ${ }^{2}$ Population Health Sciences, Bristol Medical School, University of Bristol, Canynge Hall, 39 Whatley Road, Bristol BS8 2PS, England. ${ }^{3}$ The Behaviouralist Ltd, 5 Hoxton Square, London N1 6NU, England. ${ }^{4}$ Appetite Control and Energy Balance Group, School of Psychology,

University of Leeds, Leeds LS2 9JT, England.

Received: 13 December 2017 Accepted: 28 June 2018

Published online: 09 July 2018

\section{References}

1. Swinburn BA, Sacks G, Hall KD. Obesity 1 the global obesity pandemic: shaped by global drivers and local environments. Lancet. 2011;378:804-14.

2. World Health Organisation, http://www.who.int/topics/obesity/en/. Accessed August 2017

3. Nederkoorn C, Smulders FTY, Jansen A. Cephalic phase responses, craving and food intake in normal subjects. Appetite. 2000;35:45-55.

4. Stoeckel LE, Weller RE, Cook WElll, Tweig DB, Knowlton RC, Cox JE. Widespread reward-system activation in obese women in response to pictures of high-calorie foods. Neurolmage. 2008:41:636-47.

5. Fedoroff IDC, Polivy J, Herman CP. The effect of pre-exposure to food cues on the eating behavior of restrained and unrestrained eaters. Appetite. 1997;28:33-47.

6. Hollands GJ, et al. The TIPPME intervention typology for changing environments to change behaviour. Nat Hum Behav. 2017;1:1-9.

7. Custers R, Aarts H. Positive affect as implicit motivator: on the nonconscious operation of behavioral goals. JPersSocPsychol. 2005;89:129-42.

8. Stroebe W, van Koningsbruggen GM, Papies EK, Aarts H. Why most dieters fail but some succeed: a goal conflict model of eating behavior. Psychol Rev. 2013;120:110-38.

9. Brunner TA, Siegrist M. Reduced food intake after exposure to subtle weight-related cues. Appetite. 2012;58:1109-12.

10. Sellahewa DA, Mullan B. Health behaviours and their facilitation under depletion conditions: the case of snacking. Appetite. 2015;90:194-9.

11. Stampfli AE, Stockli S, Brunner TA. A nudge in a healthier direction: how environmental cues help restrained eaters pursue their weight-control goal. Appetite. 2017;1 10:94-102.

12. Buckland NJ, Finlayson G, Edge R, Hetherington MM. Resistance reminders: dieters reduce energy intake after exposure to diet-congruent food images compared to control non-food images. Appetite. 2014;73:189-96.

13. Buckland NJ, Finlayson G, Hetherington MM. Slimming starters. Intake of a diet-congruent food reduces meal intake in active dieters. Appetite. 2013;71:430-7. 
14. Boland WA, Connell PM, Vallen B. Time of day effects on the regulation of food consumption after activation of health goals; study 2. Appetite. 2013;70:47-52

15. Versluis I, Papies EK. Eating less from bigger packs: preventing the pack size effect with diet primes; study 2. Appetite. 2016;100:70-9.

16. Papies EK, Hamstra P. Goal priming and eating behavior: enhancing selfregulation by environmental cues. Health Psychol. 2010;29:384-8.

17. Papies EK. Health goal priming as a situated intervention tool: how to benefit from nonconscious motivational routes to health behaviour. Health Psychol Rev. 2016;10:408-24.

18. Pelaez-Fernandez MA, Extremera N. The control dilemma in eating behavior: influence of temptation cues in restrained versus unrestrained eaters. Psicothema. 2011;23:587-92.

19. Harris JL, Bargh JA, Brownell KD. Priming effects of television food advertising on eating behavior. Health Psychol. 2009;28:404-13.

20. Seddon L, Berry N. Media-induced disinhibition of dietary restraint. British $J$ Health Psychol. 1996;1:27-33.

21. Mills JS, Polivy J, Herman CP, Tiggemann M. Effects of exposure to thin media images: evidence of self-enhancement among restrained eaters. Personal Soc Psychol Bull. 2002;28:1687-99.

22. Boyce JA, Kuijer RG, Gleaves DH. Positive fantasies or negative contrasts: the effect of media body ideals on restrained eaters' mood, weight satisfaction, and food intake. Body Image. 2013;10:535-43.

23. Buckland NJ. Are diet-congruent odour cues always fruitful?: Effects of dietcongruent food odours on snack intake in 'The role of diet-congruent cues in short term food intake.' 2013; White Rose eThesis Online. http://etheses. whiterose.ac.uk/id/eprint/6333.

24. Blundell JE, Finlayson G, Halford J, Hetherington MM. King, N. In: Handbook of assessment methods for eating behaviors and weight related problems. London: Sage; 2009. p. 283-325.

25. Macdiarmid J, Blundell J. Assessing dietary intake: who, what and why of under-reporting. Nutr Res Rev. 1998:11:231-53.

26. Albarracin D, Wang W, Leeper J. Immediate increase in food intake following exercise messages. Obesity. 2009;17:1451-2.

27. Jansen A, de Vries M. Pre-attentive exposure to the thin female beauty ideal does not affect women's mood, self-esteem and eating behaviour. Eur Eat Disord Rev. 2002;10:208-17.

28. Boyce JA, Kuijer RG. Focusing on media body ideal images triggers food intake among restrained eaters: a test of restraint theory and the elaboration likelihood model. Eat Behav. 2014;15:262-70.

29. Bourn R, Prichard I, Hutchinson AD, Wilson C. Watching reality weight loss TV. The effects on body satisfaction, mood, and snack food consumption. Appetite. 2015;91:351-6.

30. Strahan EJ, Spencer SJ, Zanna MP. Don't take another bite: how sociocultural norms for appearance affect women's eating behavior. Body Image. 2007:4:331-42.

31. Himes $\mathrm{S}$. Examining an acute environmental trigger for dysfunctional eating: measuring the immediate impact of fat disparagement media exposure and its effects on body dissatisfaction, negative affect, weight control practice intentions, and sub-clinical binge eating behavior in college women. Dissertation Abstracts International: Section B: The Sciences and Engineering. 2011;71:5792.

32. Harrison KT, Laramie D, Marske AL. Women's and Men's eating behavior following exposure to ideal-body images and text. Commun Res. 2006;33:507-29.

33. Cohen J. A power primer. Psychol Bull. 1992;112:155-9.

34. Higgins JP, Thompson SG, Deeks JJ, Altman DG. Measuring inconsistency in meta-analyses. Br Med J. 2003;327:557-60.

35. Egger M, Davey Smith G, Schneider M, Minder C. Bias in meta-analysis detected by a simple, graphical test. Br Med J. 1997;315:629-34

36. Duval S, Tweedie R. Trim and fill: a simple funnel-plot-based method of testing and adjusting for publication bias in meta-analysis. Biometrics. 2000;56:455-63.

37. Higgins JPT, Altman DG, Gøtzscheet PC, Jüni $P$, Moher D, Oxman AD, Savović H, Schulz KF, Weeks L, Sterne JAC. Cochrane Bias Methods Group, Cochrane Statistical Methods Group The Cochrane Collaboration's tool for assessing risk of bias in randomised trials. British Medical Journal. 2011;343. https://doi.org/10.1136/bmj.d5928.

38. Blundell J, De Graaf CD, Hulshof T, Jebb S, Livingstone B, Lluch A, et al. Appetite control: methodological aspects of the evaluation of foods. Obes Rev. 2010;11:251-70
39. Herman CP, Roth DA, Polivy J. Effects of the presence of others on food intake: a normative interpretation. Psychol Bull. 2003;129:873-86.

40. Stein AT, Greathouse $\sqcup$, Otto MW. Eating in response to exercise cues: role of self-control fatigue, exercise habits, and eating restraint. Appetite 2016;96:56-61.

41. Minas RK, Poor M, Dennis AR, Bartelt VL. A prime a day keeps calories away: the effects of supraliminal priming on food consumption and the moderating role of gender and eating restraint. Appetite. 2016;105:494-9.

42. van Kleef E, Shimizu M, Wansink B. Food compensation: do exercise ads change food intake? Int. J. Behav Nutr Phys Act. 2011;8:6

43. Stampfli AE, Brunner TA. The art of dieting: exposure to thin sculptures effortlessly reduces the intake of unhealthy food in motivated eaters. Food Qual Prefer. 2016;50:88-93.

44. Werle COC, Birau MM, Lasaleta JD. Watching easy sports makes me eat more. Food Qual Prefer. 2017:60:132-7.

45. Forster J, Liberman N, Friedman RS. Seven principles of goal activation: a systematic approach to distinguishing goal priming from priming of non-goal constructs. J Pers Soc Psychol. 2007;11:211-33.

46. Papies, Stroebe $\mathbf{W}$, Aarts $\mathrm{H}$. Healthy cognition: processes of self-regulatory success in restrained eating. Personal Soc Psychol Bull. 2008;34:1290-300.

47. Reid M, Hammersley R, Rance J. Restraint, dieting and watching what you eat amongst female students. Nutr Bull. 2005:30:120-5.

48. Alberts HJEM, Thewissen R, Raes L. Dealing with problematic eating behaviour. The effects of a mindfulness-based intervention on eating behaviour, food cravings, dichotomous thinking and body image concern. Appetite. 2012;58:847-51.

49. Forman EM, Hoffman KL, Juarascio AS, Butryn ML, Herbert JD. Comparison of acceptance-based and standard cognitive-based coping strategies for craving sweets in overweight and obese women. Eat Behav. 2013;14:64-8.

50. Robinson E, Bevelander KE, Field M, Jones A. Methodological and reporting quality in laboratory studies of human eating behavior. Appetite. 2018;125:486-91.

51. Casazza K, Fontaine KR, Astrup A, Birch LL, Brown AW, Bohan Brown MM, et al. Myths, presumptions and facts about obesity. N Engl J Med. 2013:368:446-54.

52. Marteau TM, Ogilvie D, Roland M, Suhrcke M, Kelly MP. Judging nudging: can nudging improve population health? BMJ. 2011;342:263.

53. Robinson E, Higgs S, Daley AJ, Jolly K, Lycett D, Lewis A, et al. Development and feasibility testing of a smart phone based attentive eating intervention. BMC Public Health. 2013;13:639.

54. McFerran B, Dahl DW, Fitzsimons GJ, Morales AC. Might an overweight waitress make you eat more? How the body type of others is sufficient to alter our food consumption. J Consum Psychol. 2010;20:146-51.

55. Kroese FM, Adriaanse MA, Evers C, De Ridder DTD. "Instant success": turning temptations into cues for goal-directed behavior. Personal Soc Psychol Bull. 2011:37:1389-97.

56. Gortmaker SL, et al. Obesity 4 changing the future of obesity: science, policy, and action. Lancet. 2011:378:838-47.

57. Herman CP, Polivy J. Restrained eating. In: Stunkard AJ, editor. Obesity. Philadelphia: Saunders; 1980. p. 208-25.

58. Stunkard AJ, Messick S. The three-factor eating questionnaire to measure dietary restraint, disinhibition and hunger. J Psychosom Res. 1985;29:71-83.

59. Higgins ET, Bond RN, Klein R, Strauman T. Self-discrepancies and emotional vulnerability - how magnitude, accessibility, and type of discrepancy influence affect. J Pers Soc Psychol. 1986;51:5-15.

60. Dinkel A, Berth H, Exner C, Rief W, Balck F. Deutsche Adaptation der Restrain Scale zur Erfassung gezügelten Essverhaltens. Diagnostica. 2005:51:67-74.

61. Wegner DM, Schneider DJ, Carter SR, White TL. Paradoxical effects of thought suppression. J Pers Soc Psychol. 1987;53:5-13.

62. Anschutz DJ, Van Strien T, Engels RCME. Exposure to slim images in mass media: television commercials as reminders of restriction in restrained eaters. Health Psychol. 2008;27:401-8.

63. Strauss J, Doyle AE, Kreipe RE. The paradoxical effect of diet commercials on reinhibition of dietary restraint. J Abnorm Psychol. 1994;103:441-4.

64. Heatherton TF, Polivy J. Development and validation of a scale for measuring state self-esteem. J Pers Soc Psychol. 1991;60:895-910. 